E UROPEAN CENTRAL BANK

WORKING PAPER SERIES

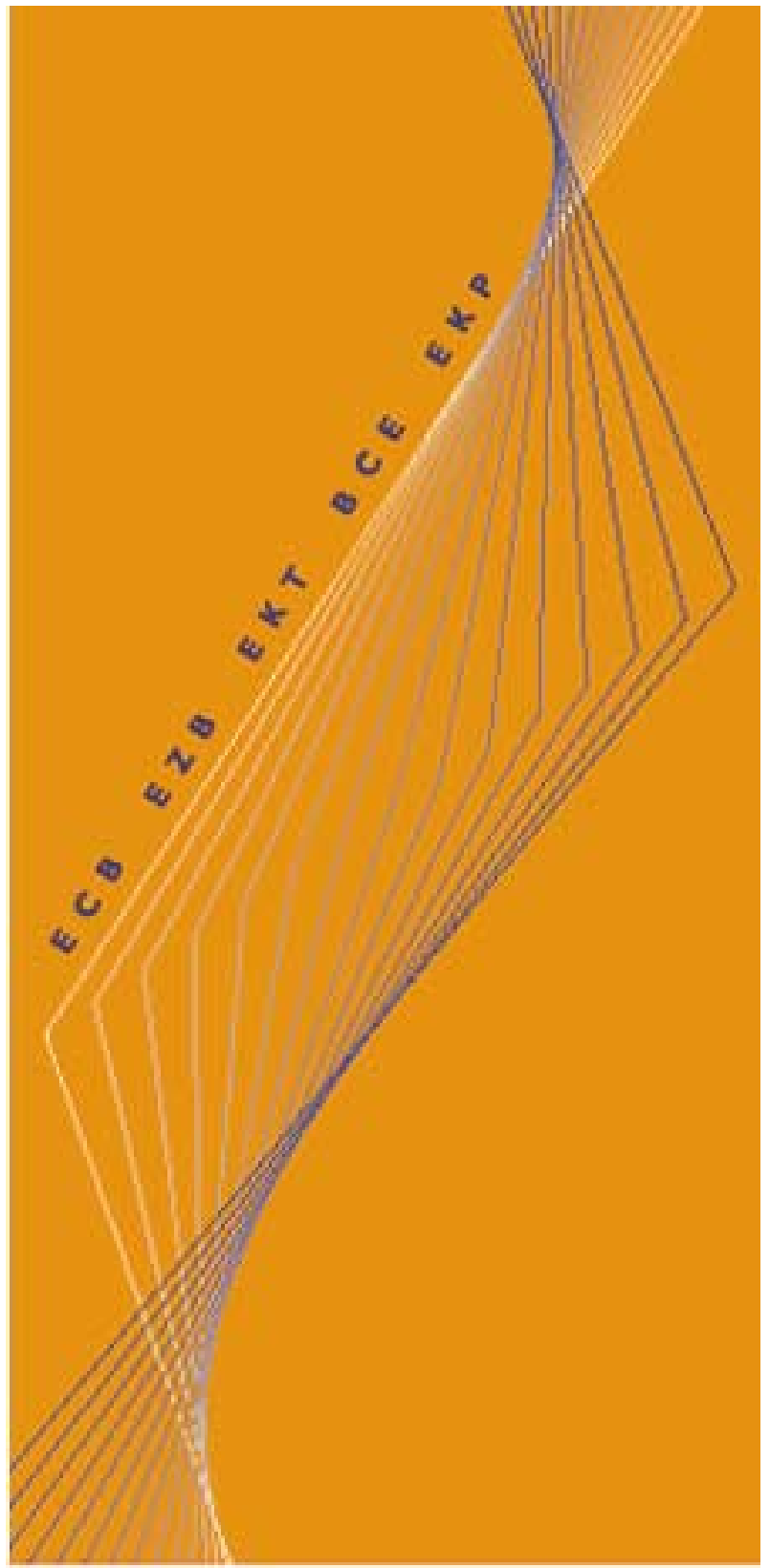

WORKING PAPER NO. 53

\title{
AN EVALUATION OF SOME MEASURES OF CORE INFLATION FOR THE EURO AREA
}

BY JUAN-LUIS VEGA AND MARK A. WYNNE 

E U R P E A N E N T R L B A N K

WORKING PAPER SERIES

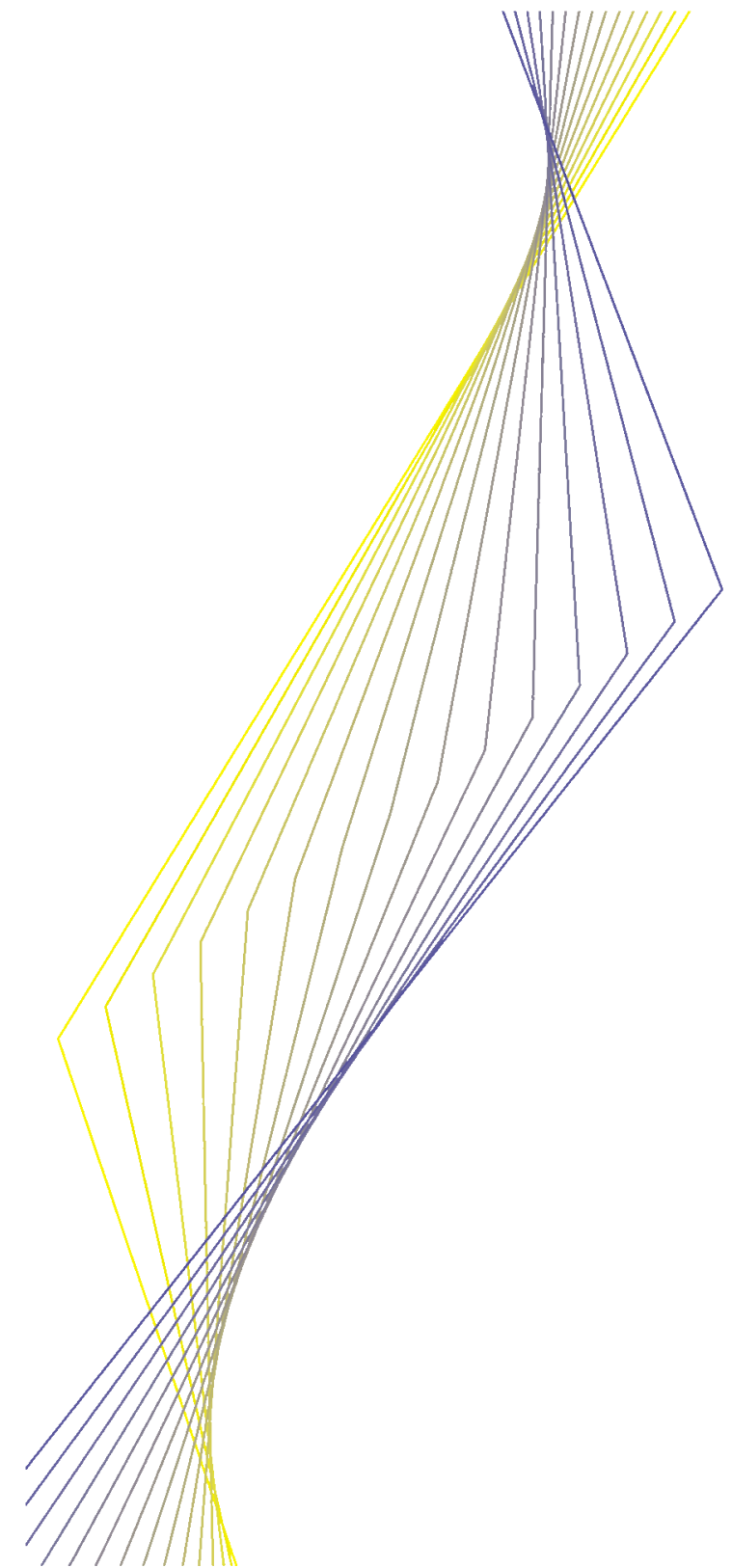

WORKING PAPER NO. 53
AN EVALUATION OF
SOME MEASURES OF
CORE INFLATION FOR
THE EURO AREA*

BY JUAN-LUIS VEGA

AND MARK A. WYNNE

April 2001 
(C) European Central Bank, 200 I

$\begin{array}{ll}\text { Address } & \text { Kaiserstrasse } 29 \\ & \text { D-603 I I Frankfurt am Main } \\ & \text { Germany } \\ & \text { Postfach } 1603 \text { I9 } \\ \text { Postal address } & \text { Germany } \\ & +4969 \text { I344 } 0 \\ \text { Telephone } & \text { http://www.ecb.int } \\ \text { Internet } & +4969 \text { I344 } 6000 \\ \text { Fax } & 41 \text { I I44 ecb d } \\ \text { Telex } & \end{array}$

All rights reserved.

Reproduction for educational and non-commercial purposes is permitted provided that the source is acknowledged.

The views expressed in this paper are those of the authors and do not necessarily reflect those of the European Central Bank.

ISSN I56I-08I0 


\section{Contents}

\begin{tabular}{ll} 
Abstract & 4 \\
\hline
\end{tabular}

Executive Summary 5

\begin{tabular}{lll}
\hline Introduction & 7
\end{tabular}

2 Data and other preliminaries 9

$3 \quad$ Three measures of core inflation $\quad 13$

$\begin{array}{lll}4 & \text { Criteria for evaluation I: tracking trend inflation } & 16\end{array}$

$\begin{array}{lll}5 & \text { Criteria for evaluation II: forecasting future inflation } & 19\end{array}$

6 Conclusions and directions for research 20

$\begin{array}{lr}\text { References } & 22\end{array}$

\begin{tabular}{lr} 
Tables & 24 \\
\hline
\end{tabular}

\begin{tabular}{lr} 
Figures & 30 \\
\hline
\end{tabular}

$\begin{array}{ll}\text { European Central Bank Working Paper Series } & 40\end{array}$ 


\section{Abstract}

We examine two measures of core inflation which have been proposed in recent years: the limited-influence estimators of core inflation pioneered by Bryan and Cecchetti (1994); and the Edgeworth or variance-weighted price index discussed by Diewert (1995). We compare these measures with traditional "Ex. Food \& Energy"-type measures and evaluate them on the basis of two criteria: their ability to track movements in trend inflation; and their ability to predict future headline inflation. We do find evidence that traditional "Ex. Food \& Energy"-type measure of core inflation may be dominated by alternative measures and conclude that trimmed-mean measures of core inflation may be a useful input to the monetary policy process. These conclusions, nonetheless, are necessarily tentative and subject to strong caveats due to the short span of data on which inference can be drawn.

Keywords: euro area, HICP, core inflation JEL Classification System: E3 I 


\section{Executive Summary}

Since the 1970s it has been routine for national statistical agencies and central banks to report and analyse an array of so-called core inflation measures that are supposed give a better indication of the underlying inflation trend than the headline inflation rate. At the most basic level, this typically involves eliminating regular seasonal fluctuations in certain classes of prices by statistical means. However further adjustments are typically also made, such as the exclusion of certain categories of prices on the grounds that they are too volatile to convey any useful information about underlying trends, and case-by-case adjustments for first-round effects of one-off special shocks, such as major changes in VAT. By far the most common and closely-watched measures of core inflation are the so-called exclusion-based measures, specifically the "Ex. Food \& Energy"-type measures constructed and reported by most statistical agencies. But in recent years there has been growing interest in alternative measures of core inflation.

This paper focuses on one of the newer approaches to core inflation measurement, namely that of isolating the common (inflation) component in monthly price statistics. We examine two measures of core inflation which have been proposed in recent years: the limited-influence estimators of core inflation pioneered by Bryan and Cecchetti (1994); and the Edgeworth or variance-weighted price index discussed by Diewert (1995). We compare these measures with traditional "Ex. Food \& Energy"-type measures and evaluate them on the basis of two criteria. First, we look at their ability to track movements in trend inflation. Changes in trend inflation are usually only apparent long after they have occurred, so any measures of core inflation that speed the identification of these changes would clearly be useful to monetary policy makers. Second, we look at the ability of various core measures to predict future headline inflation. Forward-looking monetary policy needs to be pre-emptive, so a measure of core inflation that helped forecast future headline inflation would be a useful input to the monetary-policy making process. Our objective is to see whether the limited-influence or Edgeworth measures of core inflation can deliver better performance than the traditional "Ex. Food \& Energy" measures in terms of these criteria.

The biggest obstacle to a rigorous evaluation of the performance of different measures of core inflation for the euro area is the short history of the Harmonised Indexes of Consumer Prices (HICP). Aggregate HICP data are only available back to 1990, while details of the component price series are only available from 1995. Thus any conclusions will of necessity be tentative and subject to strong caveats. With that in mind, we do find evidence that traditional "Ex. Food \& Energy"-type measure of core inflation may be dominated by alternative measures.

First we show that the distribution of individual price changes in the euro area at any point in time tends to be highly skewed. That is, in any one month some prices tend to rise (or fall) a lot more than others. This characteristic of the distribution of individual price changes means that it may be possible to obtain a better estimate of the true average price change by methods other than simple averaging. Specifically, by eliminating the most extreme price changes and averaging what is left, one computes a limited-influence estimator of the average price change. We show that such measures of core inflation tend to do a better job at tracking trend inflation (and forecasting future inflation) than does the traditional “Ex. Food \& Energy"-type measure.

An alternative to discarding some prices when computing the core inflation rate (food and energy prices with traditional measures, the most extreme price changes with the trimmed mean measure) is to simply assign a smaller weight to those prices that change the most frequently. This is what the Edgeworth measure does. We show that the performance of such a measure of core inflation for the euro area is not very impressive over our sample period. One reason for this may be that this measure of core inflation may be slow to respond to changes in the volatility of different prices. 
Why does the trimmed-mean measure do so well? To begin with, we show that the prices of several categories of goods and services are as volatile as those routinely excluded from a traditional "Ex. Food \& Energy"-type measure (specifically the "Ex. Energy and Seasonal Food" measure of core). So in terms of detecting shifts in trend inflation, not infrequently it will be the prices of goods and services other than food and energy that need to be discarded to get a clearer picture of what is going on. Furthermore, by discarding prices on the basis of their current behaviour rather than historical patterns, the trimmed-mean measure is quicker to respond to changes in the volatility of individual prices. By contrast, the Edgeworth measure is more backward looking.

Our (necessarily tentative) conclusion is that, in terms of tracking trend inflation and forecasting future headline inflation, trimmed-mean measures of core inflation are a useful input to the monetary policy process. 
Central bankers have long accepted that, in view of the lags in the transmission mechanism and the medium-term orientation of monetary policy, short-term, transient, inflation developments should not, in principle, unduly affect monetary policy decisions. One practical implication of this is the need that arises for monetary-policy makers to be able to decompose headline inflation figures into a trend component reflecting persistent sources of inflationary pressures, on the one hand, and a transient, reversible, component, on the other. It is the first of these components - customarily referred to as underlying or core inflation - that incorporates the most relevant information from the perspective of a monetary-policy maker.

In the light of these policy needs, it is now routine for national statistical agencies and central banks to report and analyse an array of so-called core inflation measures that are supposed to give a better indication of the underlying inflation trend. At the most basic level, this typically involves eliminating regular seasonal fluctuations in certain classes of prices by statistical means. However further adjustments are typically also made, such as the exclusion of certain categories of prices on the grounds that they are too volatile to convey any useful information about underlying trends, and case-by-case adjustments for first-round effects of one-off special shocks, such as major changes in VAT. By far the most common and closely watched measures of core inflation are the so-called exclusion-based measures, specifically the "Ex. Food \& Energy"-type measures constructed and reported by most statistical agencies. But in recent years there has been growing interest in alternative measures of core inflation.

The newer literature on core inflation has developed along two lines, reflecting different philosophies of what it is core inflation measures should be capturing. One strand of the new literature seeks to bring some discipline to the practice of downweighting certain price observations by excluding them from the measure of core. This strand can be traced to the pioneering contributions of Bryan and Pike (1991) and Bryan and Cecchetti (1994), and argues that accurate measures of core inflation can be constructed on the basis of the properties of the cross-section distribution of price changes at a given point in time. A second strand defines core inflation as the persistent component of inflation, and explores ways in which this component can be isolated. The seminal paper in this vein of literature is Quah and Vahey (1995), and the thrust of this vein of the literature is that core inflation measures need to be based on the time-series properties of inflation and its determinants. Both of these approaches are surveyed and critiqued in Wynne (1999).

The various approaches suggested in the literature differ from each other in the information set which is considered to be relevant for estimating the underlying rate of inflation: whether or not the cross-section distribution of reported individual prices may be informative; whether or not the time-series properties of observed individual prices or the aggregate price level are to be taken into account; and, whether or not the information set should be widened to consider the interplay of economic variables other than prices themselves. As a consequence, the estimation techniques (and the identifying assumptions) used by each approach differ according to the various answers to such questions. It is fair to say that no consensus has yet emerged on how best to proceed on the empirical side.

This paper focuses on the approach to core inflation measurement developed in the first strand of the newer literature, namely that of isolating the common (inflation) component in monthly price statistics. We will examine a particular subset of the various empirical measures which have been proposed: the limited-influence estimators of core inflation of the sort proposed by Bryan and Pike (1991), Bryan and Cecchetti (1994) and Bryan Cecchetti and Wiggins (1997); the Edgeworth 
or variance weighted price index proposed by Diewert (1995) and Dow (1994) and implemented by Dow (1994) and Wynne (1997,200I). We will compare the properties and performance of these measures of core inflation with the traditional "Ex. Food \& Energy" measure that has been computed by many national statistical agencies since the 1970s.

The short history behind the HICP makes measures based on the information contained in the cross-section distribution of price changes of utmost interest to the ECB. Besides those particular circumstances, the traditional motivation for looking at limited-influence estimators such as trimmed means is the observed tendency for the distribution of individual price changes to exhibit significant skewness and kurtosis at any particular point in time. This fact has been documented for many countries, by, among others Balke and Wynne (2000), Ball and Mankiw (1995), Bryan, Cecchetti and Wiggins (1997), and Vining and Elwertowski (1976). The observed skewness in the cross-section distribution of price changes can be used to motivate a statistical and an economic argument for limited-influence estimators of core inflation. The statistical argument is that the observed skewness reflects kurtosis in the underlying distribution of price changes, and in the presence of such kurtosis, a limited-influence estimator of the mean (such as the median or a trimmed sample mean) is a more efficient estimator of the population mean. The economic argument is based on the idea that there may be menu costs associated with changing prices. In the presence of such menu costs, firms will only choose to reset prices after they experience a cost shock if the shock is sufficiently large. A large transitory cost shock that causes a large number of firms to adjust their prices in the same direction at the same time may lead to a measured rate of inflation that is significantly greater or less than the underlying or trend rate. By trimming those price changes in the tails of the distribution, one presumably arrives at a more accurate measure of the underlying rate of inflation. Whether one motivates the use of a limited-influence estimator of core inflation on statistical or economic grounds, in either case the idea is that extreme price movements convey relatively little information about the underlying inflation process. This is also the idea behind the Edgeworth measure, except that in the case of the Edgeworth measure, instead of discarding the biggest and smallest price changes each period, we simply assign a lower weight to the prices that tend to fluctuate the most. The differences between the various measures will be made more precise in the discussion below.

We will use two criteria to evaluate the different measures of core inflation. First, we evaluate core measures in terms of their ability to track movements in trend inflation, with the trend estimated using a centred moving average of past, current and future values of headline inflation. This is the criterion used by Cecchetti (1997) and Bryan, Cecchetti and Wiggins (1997) to evaluate core measures. Second, we look at the ability of various core measures to predict future headline inflation. This criterion is emphasised by, among others, Blinder (1997), Freeman (1998) and Cogley (2000). The ultimate objective is to see whether the limited-influence or Edgeworth measures of core inflation can deliver better performance than traditional measures of the "Ex. Food \& Energy" type in terms of either of these criterial.

It should be borne in mind that the results in this paper are subject to the very important caveat that they are based on a sample of data on inflation and relative price changes drawn from a period in which trend inflation has been very stable and there have been no (major) relative-price shocks.

Statistical agencies routinely report inflation at several different horizons each month. Eurostat's monthly HICP release reports an annual inflation figure, a monthly inflation figure, and a I2-month average rate. The annual inflation figure is defined as the percentage change in the HICP between a given month and the same month a year earlier. The monthly inflation figure is simply the percentage change between the given month and the previous month. Both measures have competing merits. The monthly inflation number has the virtue of being the most up to date

I It should be noted that the two criteria are not unrelated, since both introduce forward-looking elements in the evaluation of the candidate measures of core inflation. 
information on inflation trends, but suffers from the drawback that it tends to be very volatile. The annual inflation number is less volatile, but achieves this reduction in volatility at a cost of being less timely. In crude terms, eleven twelfths (or more than 90 percent) of the inflation in the annual number occurred prior to the month in question, and is in a very real sense a "bygone" for monetary policy purposes. In what follows we will investigate the properties of core measures constructed at both horizons. Eurostat also reports a 12-month average inflation rate, which compares the average price level over the most recent twelve months to the level over the preceding twelve months. This measure is of limited usefulness in assessing current inflation, but does give some perspective on recent trends.

The rest of the paper is structured as follows. Section $\mathbf{2}$ describes the data used for the study and introduces some notation. Some characteristics of the cross-section distribution of individual price changes in the euro area are documented. In Section 3, the core measures under consideration are defined. In Section 4, the measures of core inflation are evaluated in terms of their ability to track trend inflation in real time. In Section $\mathbf{5}$ the measures are in turn evaluated in terms of their ability to predict future headline inflation at an eighteen-month horizon. Finally, Section 6 concludes and suggests areas for future research.

\section{Data and other preliminaries}

The primary source of raw data for this study is the Harmonised Consumer Price Index (HICP) compiled by Eurostat. Our focus on the HICP is dictated by the ECB's definition of price stability in terms of this price index. As noted in the introduction, a major shortcoming of the HICP is its short history. Estimates of the aggregate HICP index are available from January 1990. Detailed subindexes are in turn available from January 1995 for most countries and from January 1996 for France. Furthermore, insofar as we want our measures of core inflation to detect or give advance warning of changes in trend inflation, the information in this sample is very limited, as there were few significant changes in trend inflation over this period.

We define the (annualised) percentage change at date $t$ in the price of an individual good or service $i$ over horizon $h$ as

$$
\pi_{i, t}^{h}=\frac{1200}{h} \times \ln \left(\frac{p_{i, t}}{p_{i, t-h}}\right)
$$

Setting $h=I$ we obtain the (annualised) monthly inflation rate; setting $h=I 2$ we obtain the annual inflation rate. Since we will evaluate various core measures in terms of their ability to track trend inflation, we need to define what we mean by trend inflation. We will employ a definition of trend inflation based on a definition of the trend price level. Trend inflation is then defined as the centred annual growth rate of the trend in the price level:

$$
\hat{\Pi}_{t}(z)=100 \times \ln \left(\frac{\hat{P}_{t+6}^{z}}{\hat{P}_{t-6}^{z}}\right)
$$

The trend in the price level is in turn defined as a z'th-order centred geometric moving average of past and future values of the actual price level, namely: 


$$
\begin{aligned}
& \hat{P}_{t}^{z}=\left(\prod_{i=-\frac{z-1}{2}}^{\frac{z-1}{2}} P_{t+i}\right)^{\frac{1}{z}} \text { for } z=1,3,5, \ldots \\
& \hat{P}_{t}^{z}=\left(\prod_{i=-\left(\frac{z}{2}-1\right)}^{\frac{z}{2}} P_{t+i}\right)^{\frac{1}{z}} \text { for } z=2,4,6, \ldots
\end{aligned}
$$

We will use $z=24$ to define our benchmark trend. The corresponding estimates of trend inflation $\hat{\Pi}(z=24)$ entail taking a moving average of inflation over 36 months, and is equal to: ${ }^{2}$

$$
\begin{aligned}
& \hat{\Pi}_{t}(z=24)=\frac{1}{24} \Pi_{t+17}+\frac{2}{24} \Pi_{t+16}+\ldots+\frac{11}{24} \Pi_{t+7}+\frac{12}{24} \Pi_{t+6}+ \\
& +\frac{12}{24} \Pi_{t+5}+\ldots+\frac{12}{24} \Pi_{t-5}+\frac{12}{24} \Pi_{t-6}+\frac{11}{24} \Pi_{t-7}+\ldots+\frac{2}{24} \Pi_{t-16}+\frac{1}{24} \Pi_{t-17}
\end{aligned}
$$

Note that this definition of trend corresponds to the definition in Bryan, Cecchetti and Wiggins (1997) and it is used herein for comparison purposes. If we were to use $z=12$, the trend would correspond to the 12-month average inflation rate which Eurostat publishes regularly together with the annual and monthly rates as an indicator that is less sensitive to transient changes in prices. This measure was also the one used in 1998 to determine the criterion of price stability in the European Commission's and European Monetary Institute's reports on convergence. Finally, $z=3$ corresponds to the three-month moving average of 12 -month growth rates used by the ECB to monitor monetary developments on a regular basis.

One notable difference with Eurostat's and ECB's measures, however, is the use herein of centred moving averages. Centring consists in assigning a given growth rate to the intermediate point in the time period under consideration. It is deemed necessary in the present context for the different estimates of trend inflation to be synchronised with the corresponding monthly changes.

One of the arguments advanced for the use of limited-influence estimators of trend inflation has to do with the properties of the cross-section distribution of price changes at a given point in time. Specifically, in the presence of excess kurtosis (fat tails), the mean of the cross-section distribution may not necessarily be the most efficient estimate of the population mean ${ }^{3}$. Thus one of our first tasks is to characterise the cross-section distribution of individual price changes by examining a number of its moments. The q'th higher order central moments of the cross-section distribution of price changes at horizon $h$ at date $t$ is

$$
m_{q, t}^{h}=\sum_{i} w_{i, t}\left(\pi_{i, t}^{h}-\bar{\pi}_{i, t}^{h}\right)^{q}
$$

2 Note that this measure of trend turns out to be essentially identical to the measure derived from the Hodrick-Prescott filter with $\lambda=1600$ or $\lambda=4800$. While we lose 18 observations from the end of our sample because of our definition of trend, we employ it rather than the more popular Hodrick-Prescott measure because of the well-known end of sample problems associated with the latter. See, for example, Baxter and King (1999).

3 See Bryan and Cecchetti (1999a). The argument is that the probability of getting skewed samples increases with the kurtosis of the data generating process. That is, with a fat-tailed distribution, it is more likely to obtain a draw from one of the tails that is not compensated by an observation in the other tail. 
where $\bar{\pi}_{i, t}^{h}$ is the mean of $\pi_{i, t}^{h}$. The two moments that will be of most interest to us are the scaled third and fourth moments, that is the skewness and kurtosis of the distribution, defined respectively as:

$$
\begin{aligned}
& S_{t}^{h}=\frac{m_{3, t}^{h}}{\left[m_{2, t}^{h}\right]^{(3 / 2)}} \\
& K_{t}^{h}=\frac{m_{4, t}^{h}}{\left[m_{2, t}^{h}\right]^{2}}
\end{aligned}
$$

Note that if the cross-section distribution of price changes at a given point in time is generated by a normal distribution, $S_{t}^{h}$ would be equal to 0 and $K_{t}^{h}=3$.

Figure I shows the annual and monthly (non-annualised) inflation rates for the euro area from 1990 though April $2000{ }^{4}$ Inflation declined from a peak of just under 5 percent in July 1991 to less than I percent around the time of the launch of EMU, before accelerating to rates close to 2 percent in late 1999 and early 2000. The short sample period, and the behaviour of inflation over the sample period, show clearly that any measure of core inflation for the euro area that is motivated by the desire to detect changes in trend inflation will perforce be subject to major caveats. The fact that the aggregate HICP statistics are available for a longer period than the disaggregated statistics might seem to suggest that measures of core based on detecting the persistent component of inflation (for example, along the lines suggested by Quah and Vahey (1995)) might have a more solid basis. However a sample period of ten years is not really long enough to allow us to make strong statements about the behaviour of inflation at very long (infinite) horizons. Furthermore, the HICP data for the years prior to 1995 are not strictly comparable to the later data, as they are estimates based on national CPIs.

Table I presents some summary statistics for the cross-section distributions of price changes at I, 3 and 12-month horizons. It shows average values over the sample 1996:1-1999:12 for the mean, the median, the standard deviation, skewness and kurtosis for each of the euro area countries and for the euro area as a whole. ${ }^{5}$ We characterise the properties of the cross-section distribution of price changes at the maximum level of disaggregation (the four digit level which consists of eighty sub-aggregates) available for the HICP through the end of 1999. ${ }^{6}$ To characterise the behaviour of the cross-section distribution at the level of the euro area as a whole, two possibilities are considered.The first, denoted $M U(80 \times \mathrm{II})$, refers to the pool of data for the eleven countries (i.e., $80 \mathrm{xI}=880$ time series of individual price changes). The second, denoted MU (80), refers to the average area-wide data (i.e., $80 \mathrm{xI}=80$ time series of individual price changes). Finally, weighted averages of the corresponding national statistics, with weights equal to the average countries shares in MU HICP, are also shown in the table for illustrative purposes.

The main point to note from the table is the significant excess kurtosis that is present in the cross-section distribution of price changes at most horizons for all countries and for the euro area as a whole. At the euro area level, kurtosis ranges from 24.9 at the one-month horizon to 13.3 at the twelve-month horizon. Pooling the individual country data, kurtosis is even higher: 44.4 at the

4 Note that the data in this Figure refer to the original eleven members of the euro area only.

5 The main reason we truncate the sample in December 1999 is that there were significant changes in the HICP (primarily enhanced coverage) starting in January 2000.

6 Note that we actually work with only 77 of the 80 sub-aggregates. We use the three-digit aggregate 044A ("Other services related to the dwelling") rather than the individual prices 044 IA ("Refuse collection"), 0442A ("Sewerage services"), $0443 \mathrm{~A}$ ("Water supply") and 0444 ("Other services related to the dwelling") because the latter are missing for many countries. Also, we omit the series 044A for Ireland because of its anomalous behaviour. 
one-month horizon and 26.2 at the twelve-month horizon. The results in the table are comparable in many respects to those presented in Table I of Bryan, Cecchetti and Wiggins (1997). They report summary statistics for the cross-section distribution of CPI and PPI price changes in the U.S. at the 36-item and 32-item levels of aggregation respectively, albeit for a much longer sample period than we have here (1967 to 1997). ${ }^{7}$ As argued in Bryan, Cecchetti and Wiggins (1997), in the presence of excess kurtosis trimmed mean estimators are superior estimators of the central tendency of the cross-section distribution of price changes, and thus of core inflation. The second point to note from Table $I$ is that there is very little skewness on average, although contrary to what we see with kurtosis, skewness tends to increase with the horizon over which inflation is measured. However note that there is a sizeable difference between the mean and the median of the cross-section distribution of the pooled data at the one-month horizon, suggesting that the distribution may be asymmetric. Third, note that the characteristics of the cross-section distribution of prices at the euro area level are also observed at the level of individual countries in the euro area. Indeed, several authors have previously documented the characteristics of the cross-section distribution of prices in various euro area countries using national CPI data. For example, Aucremanne (2000) shows that kurtosis in the CPI data for Belgium ranges from a high of 37.8 at the one-month horizon to 29.2 at the twelve month horizon over the period 1976:61999:10. Meyler (1999) reports that the average kurtosis in the Irish CPI over the period 19761999 is 4I.5, with somewhat greater kurtosis in the latter half of his sample than in the first half. For the United Kingdom, Bakhshi and Yates (1999) show that average excess kurtosis in the crosssection distribution of the RPI over the period 1974:02-1997:07 is 28.4.

Figure 2 plots the standard deviation, skewness and kurtosis of the cross-section distribution of annual and monthly price changes in the euro area over time, both at the MU $(80 \times \mathrm{II})$ and MU (80) aggregation levels. Besides the excess kurtosis feature referred to above, the Figure shows how the cross-section distribution of price changes can be very skewed at specific points in time, particularly when monthly changes are considered. Note that the well-known relationship between skewness and average inflation is also apparent in this Figure, especially when we look at the skewness in price changes at the twelve-month horizon.

Table 2 reports the mean and standard deviations of the components of the HICP over our limited sample period. As we would expect, the volatility of individual price changes as measured by the standard deviation declines as the horizon over which inflation is measured is increased. The items that are excluded from a representative exclusion-type measure of core inflation (the "Ex. Energy and Seasonal Food" measure to be discussed in more detail later) are highlighted. Note that at the one-month horizon, the least volatile of these prices is "Solid fuels" with a standard deviation of 6.4. However, note also that there are a lot of other prices that are more volatile than the least volatile component of the "Ex. Energy and Seasonal Food" measure. Even at the I2-month horizon, where the least volatile component of the "Ex. Energy and Seasonal Food" measure is again "Solid fuels" several other prices are more volatile. A non-trivial number of prices (specifically those for "Oils and fats", "Clothing materials", "Passenger transport by air", "Passenger transport by sea and inland waterway", "Postal services", "Telephone and telefax equipment and services", "Gardening”, "Package holidays", “Accommodation services” and "Insurance connected with transport - car insurance") are more volatile at both the one-month and twelve-month horizons. This raises the possibility that an exclusion-type measure of core more comprehensive than a traditional measure of core inflation such as the "Ex. Energy and Seasonal Food" measure or an alternative measure such as the ones we will explore below may do a better job than the traditional measure. 8

7 In earlier versions of this paper we reported results at the three-digit level of the HICP which has 33 component series. The results were similar in many respects to those reported here.

8 Note that the measure of core inflation for the euro area proposed by Deutsche Bank excludes a wide range of products in addition to the usual food and energy. See Monticelli and Buttiglione (2000). 
Two conclusions can be drawn from this simple characterisation of the data:

I. There is significant excess kurtosis in the cross-section distribution of price changes in the HICP on average. This is consistent with the findings of many other authors for many other countries and time periods, and suggests that limited-influence estimators of the central tendency of the distribution may dominate the mean.

2. A significant number of components of the HICP outside of the categories usually excluded from a traditional measure of core inflation such as the "Ex. Energy and Seasonal Food" measure are as volatile, and in some cases significantly more volatile, than these components, suggesting that in terms of eliminating noise and obtaining a clearer signal about underlying trends the traditional measures may be dominated by other measures.

\section{Three measures of core inflation}

As noted in the introduction, we will consider the performance of three measures of core inflation. The first are measures of the "Ex. Food \& Energy"-type that almost all national statistical agencies have been calculating since the 1970s, the second is the trimmed mean measure proposed by Bryan and Cecchetti (1994), and the third is an Edgeworth or variance-weighted index of Diewert (1995) and Dow (1994).

These three measures of core inflation have a number of attractive features ${ }^{9}$. Starting with the traditional "Ex. Food \& Energy"-type measures, these measures (and variants thereon) have been computed for so long and receive such regular coverage in the media that they are relatively well understood. Furthermore, these measures use only contemporaneous price information and are not subject to major revisions (other than those due to data revisions). The primary drawback of these measures is that the exclusion of food and energy prices is somewhat arbitrary. As we have already noted, it is not always the case that food and energy prices are the most volatile, or contain the least information about the underlying inflation rate. The symmetric trimmed mean seeks to exclude prices on a less arbitrary basis, and can also be computed using only contemporaneous price data. The primary drawback of this measure is that it may not be easily understood by the general public. Also, it assigns zero importance to the largest price changes, which may not be appropriate. It is not difficult to imagine circumstances under which the price changes in the tails of the cross-section distribution are the most informative about changes in trend 10 . The Edgeworth measure does not discard any price information in computing core inflation, but rather makes the weights of individual prices in the overall index depend on how "noisy" they are as measured by their variability. Thus it does not discard any information in the cross-section distribution of price changes. But this measure cannot be computed solely on the basis of contemporaneous price information. It also requires data on the history of relative prices to calculate the weights, and these weights will change as we move through time. Also, this measure may suffer from the problem that it would be a relatively difficult measure to communicate to the general public.

\section{The traditional "Ex. Food \& Energy" measure}

We consider a number of exclusion-type measures. Table 3 lists a number of "Ex. Food \& Energy" or exclusion-type measures and shows the various categories of goods excluded from the different measures. These definitions exclude different groupings of food and energy products, and are presumably motivated by the experiences of statisticians in tracking individual prices. We will

9 See Wynne (1999) for a critical review

10 Bakhshi and Yates (1999), for instance, argue - quite convincingly - that the economic argument for trimming observations in the tails is model dependent. 
take as our benchmark measure in this category the "Ex. Energy and Seasonal Food" measure, which excludes the categories 0113 (Fish), 0116 (Fruit), 0117 (Vegetables including potatoes and other tubers), 045I (Electricity), 0452 (Gas), 0453 (Liquid fuels), 0454 (Solid fuels), 0455 (Hot water, steam and ice), and 0722 (Fuels and lubricants).

\section{The trimmed mean ${ }^{\prime \prime}$}

Trimmed mean measures of core inflation have been calculated for a large number of countries following the demonstration by Bryan and Cecchetti (1994) that measures of this type tend to outperform traditional measures of inflation. ${ }^{12}$ To compute the (symmetric) trimmed mean of the cross-section distribution of prices, we start by ordering the observed price changes at a particular date. Next we define the cumulative weight from I to $i$ as $W_{i, t}=\sum w_{(j), t}$, where $w_{(j), t}$ denotes the sorted $j$ 'th weight (and by definition $1 \geq w_{j, t} \geq 0$ ). This allows $\mathbf{s}^{j=1}$ us to define the index set $I_{\alpha}=\left\{i: \alpha<W_{i, t}<1-\alpha\right\}$. The $\alpha \%$ symmetric trimmed mean inflation rate is then defined as

$$
\pi_{t}^{h}(\alpha)=\frac{1}{1-2 \alpha} \sum_{i \in I_{\alpha}} w_{(i), t} \pi_{(i), t}^{h}
$$

where $\pi_{(j), t}$ is the sorted $j$ th price change. If $\alpha=0$ we obtain the weighted sample mean. For $\alpha=0.50$ we obtain the weighted sample median.

There is no reason a priori why we have to trim the same amount form both ends of the cross-section distribution of prices. A number of authors have proposed and implemented asymmetric trimmed mean measures of core inflation. This is done by defining the index set $I_{\alpha_{1}, \alpha_{2}}=\left\{i: \alpha_{1}<W_{i, t}<1-\alpha_{2}\right\}$. Now $\alpha_{1}$ denotes the amount trimmed from the lower tail of the cross-section distribution, and $\alpha_{2}$ denotes the amount trimmed from the upper tail. The $\left(\alpha_{1} \%, \alpha_{2} \%\right)$ asymmetric trimmed mean rate of inflation is then defined as

$$
\pi_{t}^{h}\left(\alpha_{1}, \alpha_{2}\right)=\frac{1}{1-\alpha_{1}-\alpha_{2}} \sum_{i \in I_{\alpha}} w_{(i), t} \pi_{(i), t}^{h}
$$

Asymmetric trimming is appropriate of the cross-section distribution exhibits positive or negative skewness on average. Roger (1997) found such persistent skewness in New Zealand, Jaramillo (1998) in Colombia and le Bihan and Franck (1999) report similar skewness in French CPI data over the period 1980-1998.

\section{The Edgeworth index}

The motivation for looking at the Edgeworth index is that there may be potentially useful information about underlying inflation trends contained in food and energy prices each month or the tails of the cross-section distribution of price changes each month, and that it is desirable to make use of that information somehow. So rather than discard food and energy prices every month in computing a measure of core, or discard the biggest and smallest changes, the Edgeworth index assigns an importance to individual price changes based on their information content. The strength of the "signal" in the monthly price change is inversely related to the volatility of the price in question, so the Edgeworth index assigns weights as:

II The presentation and notation here follows Bryan, Cecchetti and Wiggins (1997).

12 For example Japan (Bryan and Cecchetti, 1999b, Shiratsuka, 1997), the United Kingdom (Bakhshi and Yates, 1999), Belgium (Aucremanne, 2000), Ireland (Meyler, 1999), Portugal (Marques, Neves and Sarmento, 2000), Australia (Kearns, 1998), New Zealand (Roger, 1997), Columbia (Jaramillo, 1998) and France (Le Bihan and Sédillot, 1999). 


$$
w_{i, t}=\frac{\frac{1}{\sigma_{i, t}^{2}}}{\sum_{i=1}^{N} \frac{1}{\sigma_{i, t}^{2}}}
$$

where $\sigma_{i, t}^{2}$ denotes the variance of individual price changes. Dow (1994) and Wynne (200I) have estimated indexes of this type for the US. Diewert (1995) shows that, conditional on a specific model of price changes, ${ }^{13}$ a maximum likelihood estimate of the Edgeworth index in a sample of $T$ observations of $N$ individual price changes is given by the following $(T+N)$ equations:

$$
\begin{gathered}
\hat{\Pi}_{t}^{E}=\frac{\sum_{i=1}^{N} \frac{\pi_{i, t}}{\hat{\sigma}_{i, t}^{2}}}{\sum_{i=1}^{N} \frac{1}{\hat{\sigma}_{i, t}^{2}}} \text { for } t=1, \ldots, T \\
\hat{\sigma}_{i, t}^{2}=\frac{1}{T} \sum_{t=1}^{T}\left(\pi_{i, t}-\hat{\Pi}_{t}^{E}\right)^{2} \quad \text { for } \quad i=1, \ldots, N
\end{gathered}
$$

We compute the Edgeworth index by iterating on the above equations, starting with an initial estimate of $\hat{\Pi}_{t}^{E}$ as a simple mean of the cross-section distribution of price changes at each date.

An important choice that needs to be made in implementing this measure is the information to be used in computing the variances of individual price changes. One option is to estimate the variances using all sample information. The problem with this approach is that it may give the Edgeworth index an unfair advantage when evaluating its ability to track trend inflation in real time. Alternatively we could fix the number of observations used to calculate the variances at some value $\tau \leq T$ and hold this number constant as we move through the sample. That is

$$
\begin{aligned}
\hat{\Pi}_{t}^{E}(\tau) & =\frac{\sum_{i=1}^{N} \frac{\pi_{i, t}}{\hat{\sigma}_{i, t}^{2}(\tau)}}{\sum_{i=1}^{N} \frac{1}{\hat{\sigma}_{i, t}^{2}(\tau)}} \text { for } t=\tau, \ldots, T \\
\hat{\sigma}_{i, t}^{2}(\tau) & =\frac{1}{\tau} \sum_{s=t-\tau+1}^{\tau}\left(\pi_{i, s}-\hat{\Pi}_{s}^{E}(\tau)\right)^{2} \quad \text { for } i=1, \ldots, N
\end{aligned}
$$

Marques, Neves and Sarmento (2000) estimate a core inflation measure of this type for Portugal for the period 1993-1999. However they weight the individual price changes by the inverse of their standard deviations rather than their variances. It is possible to devise further variants on this measure. One possibility would be to downweight older observations in calculating the variances and assign a higher weight to more recent observations. However, given the extremely short sample of data we have to work with, we did not experiment with alternative values of $\tau$ but simply set it equal to 24 .

13 Specifically $\pi_{i, t}=\Pi_{t}+\varepsilon_{i, t}$, with $E\left(\varepsilon_{i, t}\right)=0$ and Var $\left(\varepsilon_{i, t}\right)=\sigma_{i}^{2}$ for $i=I, \ldots, N ; t=I, \ldots, T$. 
The first step in our evaluation of different measures of core inflation is to look at how well the various measure do at tracking trend inflation over the short period for which we have data. We start with a definition of trend as a 36-month moving average of the headline price level, and we evaluate different measures on the basis of their ability to track this trend as measured by the root mean square error statistic:

$$
M S E=\sqrt{\frac{1}{T} \sum_{t=1}^{T}\left(\Pi_{t}^{*}-\hat{\Pi}_{t}(z)\right)^{2}}
$$

where $\Pi_{t}^{*}$ is our candidate measure of trend core inflation at date $t$ and $\hat{\Pi}_{t}(z)$ is our measure of trend inflation which, as defined above, corresponds to a centred 36-month moving average of inflation $\hat{\Pi}_{t}(24)$.

Figure 3 shows the performance, in the terms described above, of the trimmed mean estimators as a function of the trim, along with the RMSE for the "Ex. Energy and Seasonal Food" measure. The trimmed means referred to in the figure correspond to the result of compounding the monthly trimmed means over the last twelve months. The "Ex. Energy and Seasonal Food" measure refers in turn to the annual change in this measure. The exercise in Figure 3 is conducted for two levels of aggregation, i.e. four- and three-digit levels, and for both the pooled country data and the average area-wide data.

Figure 3a shows the results at the most disaggregated level, i.e. the 80-item or four-digit level for all eleven countries in the euro area. At this level of disaggregation, the trimmed means do not uniformly dominate the traditional measure. For example, the RMSE for the median $(50 \%$ trim) is about 0.5 , as opposed to 0.22 for the traditional measures. However, a trim of $5-10 \%$ does yield better performance than the traditional measure, lowering the RMSE from 0.22 to 0.14 . If instead of working up from the country level data we focus on the MU level disaggregated series, we obtain very different results. Now, as Figure $3 \mathrm{~b}$ shows, the trimmed mean dominates the traditional measure for any amount of trimming. The optimal trim is anything in excess of $15 \%$, and the gain is a reduction in the RMSE of about $75 \%$. If instead we focus on the higher (three-digit) level of aggregation, as in Figures $3 \mathrm{a}$ and $3 \mathrm{~b}$, we see strikingly similar patterns although the gains from trimming are a lot smaller.

How do these measures look in real time? Figure 4 shows the three measures, along with trend and headline inflation over the past three years. Note that the estimated trend does not extend through the end of the sample period due to our use of a two-sided measure. At the four-digit level of disaggregation, using only the MU level data, the optimally trimmed mean tracks trend inflation quite well, and does a lot better than the "Ex. Energy and Seasonal Food" measure. At the three-digit level, the performance is less impressive. The two right panels show the extent to which the various measures overstate or understate trend inflation. At both the three digit and four digit levels, the traditional measure performs quite poorly.

An alternative way of looking at the ability of these measures to track the trend is to calculate their average bias. Figure 5 shows the average bias as a function of trim for the trimmed mean measure, along with the average bias of the "Ex. Energy and Seasonal Food" measure and 95\% confidence intervals. The bias is defined as the mean deviation from trend of the various core measures. Note that the "Ex. Energy and Seasonal Food" measure has a positive bias, that is, it routinely overstates trend inflation. At both the three- and four-digit levels of disaggregation, when we pool all of the country data, trimming in excess of $5 \%$ or so yields a measure that is 
systematically negatively biased. However, using the MU level data, at the four-digit level there are a wide range of trims for which the trimmed mean yields an unbiased estimate of trend, while at the three-digit level trimming up to $15 \%$ or so yields an unbiased measure.

Overall, the evidence summarised in Figures 3 to 5 allows us to draw some conclusions, tentative they may be due to the short sample available for inference. Contrary to the evidence in Bryan, Cecchetti and Wiggins (1997) trimming at an arbitrary level does not always produce efficiency gains (reduction in the RMSE) when compared to the weighted mean (headline inflation) or to the "Ex. Energy and Seasonal Food" measure. On the other hand, trimming at the estimated optimal levels does result in efficiency gains in all cases, although these turn to be more modest than those reported in Bryan, Cecchetti and Wiggins (1997) for the US.

The optimal trim appears to vary with the cross-section distribution being considered. The evidence in Figure 3 shows in this respect that quite different estimates of the optimal trim are obtained depending on the level of good and country aggregation under consideration. Results not presented here but available from previous versions of this paper ${ }^{14}$ indicates that the same holds true for the different horizons $h$ over which individual price changes can be computed (i.e. whether monthly or annual changes in individual price indices are considered) and/or for the different ways the underlying individual price changes can be computed (i.e. whether annualised monthly changes are trimmed or, alternatively, trimming is made on the basis of monthly changes which are subsequently compounded), but not quite so for alternative definitions of trend inflation 15,16 . Notwithstanding that, it appears still possible to choose one single dimension which performs best when the evaluation criteria is tracking trend inflation in real time. In this respect, the recommendation that comes out of the analysis appears to be to trim some number above $15 \%$ from each tail of the cross-section distribution of monthly changes in euro area average individual price indices at the four-digit level.

The analysis above suggests that trimming seems to dominate the traditional "Ex. Energy and Seasonal Food" measure of core in terms of its ability to track trend inflation. What of other exclusion-type measures, such as "Ex. Energy" and so on? Table 4 compares the performance of a number of traditional exclusion type-measures of core with the optimally trimmed mean. The RMSEs of these measures range from a low of 0.22 for the "Ex. Energy and Seasonal Food" measure, to a high of 0.32 for the "Ex. Energy" measure. By comparison, the RMSE of the optimal trimmed mean is only 0.07 . Likewise, in terms of bias, the exclusion-type measures range from 0.00 for "Ex. Housing, water, electricity, gas and other fuels" to 0.20 for "Ex. Liquid fuels and fuels and lubricants for personal transport equipment"; for the optimally-trimmed mean the bias is 0.02 .

What of the Edgeworth measure? Figure 6 shows the estimated Edgeworth index (using 24 months to calculate the variances of individual prices) along with trend inflation for $h=1$ at the three- and four-digit levels of aggregation using both MU level and pooled country data. The RMSE for the Edgeworth index is 0.112 at the 33-item (three-digit) level and 0.210 at the 80 -item (fourdigit) level when we use MU level data. Indeed, at the three-digit level, the Edgeworth index does a remarkably good job at tracking trend inflation, as is apparent in Figure $6 \mathrm{a}$. When we use the

14 Available from the authors upon request.

15 Bakhshi and Yates (1999) and Aucremanne (2000) report similar findings concerning the sensibility of results to the level of aggregation, the horizon and to the precise way the underlying individual price changes are calculated. As regards trend inflation, we experimented with the different proxies referred to in Section 2, i.e. $z=3,12,24$. In most cases, results do not appear to be sensitive to this choice. This is consistent with the evidence reported in Bryan, Cecchetti and Wiggins (1997) for the US.

16 The small size of the sample available to us precluded exploration of the performance of the trimmed mean type measures along a number of other dimensions. Most importantly, it has not been possible to investigate whether the estimated optimal trims are constant over time. Lack of stability has been reported in Bakhshi and Yates (1999) for the UK and Aucremanne (2000) for Belgium. On the other hand, Roger (1997) and Bryan, Cecchetti and Wiggins (1997) report the optimal trim to be quite stable in New Zealand and the US, respectively. Also, we have not explored either the sensitivity of our results to the use of seasonally adjusted data. See Aucremanne (2000) for evidence on the latter. 
pooled country data to build up the Edgeworth measure, its performance is less impressive. At the three-digit level, it understates trend. At the four-digit level, the tendency to understate the trend is apparent in both the MU level data and the pooled country data. A comparison of Figures $6 \mathrm{c}$ and $6 \mathrm{~d}$ shows that there is little difference in the estimates of the Edgeworth index when we use MU or pooled country data. The RMSEs using the pooled country data are 0.388 at the three-digit level and 0.218 at the four-digit level. Thus the Edgeworth index would appear to dominate the "Ex. Energy and Seasonal Food" measure, but is itself dominated by the optimally trimmed mean. The poor performance of the Edgeworth measure is a little surprising, as one might expect a priori a measure that uses all available information about price changes to do better at tracking trend inflation than measures that discard information in one way or another. One possibility is that the sample of data we have to work with is simply too short to allow robust estimation of the variances of individual price series. Another possibility is that the measure is permanently handicapped by the backward-looking way in which it assigns weights to individual price changes.

That the traditional "Ex. Energy and Seasonal Food" measure (and other measures of this type) is dominated by the trimmed mean should not be surprising, given our earlier demonstration that the prices of a large number of goods and services seem to as volatile, or in some cases a lot more volatile, as the categories of prices that are excluded from the "Ex. Energy and Seasonal Food" measure. In Table 5 we report the percentage of the time that the price of a particular good or service is excluded from the bottom of the distribution, the percentage of time it is excluded from the top of the distribution, the percentage of time it is excluded overall and the percentage of time it is included. Note first of all that of the nine categories of prices that are excluded from the "Ex. Energy and Seasonal Food" measure, only one of them, "Liquid fuels", is selected by the trimming procedure to be always excluded. Furthermore, the trimming procedure selects three other categories of prices that are not excluded from core inflation by the traditional measure to always be excluded when calculating core inflation (namely "Equipment for the reception, recording and reproduction of sound and pictures", "Data processing equipment" and "Gardening"). Note also that no price is always included in the core measure - the price that is included the most frequently is that of "Bread and cereals" (included $85.1 \%$ of the time).

The bottom line here would appear to be that the trimmed mean does a lot better at tracking trend inflation than either of the alternatives. Before concluding this section, it is worth asking whether it is possible to do even better, by employing an asymmetric trimmed mean. Recall that asymmetric trimming may be appropriate is the cross-section distribution of prices is not symmetric on average. In Table I we documented some tentative evidence of asymmetry at the one- and twelve-month horizons. Specifically at the one-month horizon, the mean of the crosssection distribution at the 80 -item (four-digit) level in the pooled country data averaged I.4 over the period 1996:1-1999:12, while the median averaged 0.7. In the euro area data, the difference between the two measures was less significant, the mean averaging 1.4 and the median averaging I.3. At the twelve-month horizon, there is also relatively little difference between the average values of the mean and median, but there are other signs of asymmetry, as indicated by average skewness of -1.0 in the pooled country data and -0.7 in the euro area data. Thus we decided to explore the gains from asymmetric trimming of prices.

The results are reported in Figure 7, which depicts the RMSE as a function of the amount trimmed from each tail. Recall from the definition of the asymmetric trimmed mean that $\alpha_{1}$ denotes the amount trimmed from the left tail of the distribution and $\alpha_{2}$ denotes the amount trimmed from the right tail. It is immediately obvious from the four panels that the greatest gains from asymmetric trimming are at the twelve-month horizon. At this horizon, in the euro area aggregates

17 Specifically, the $\left(\alpha_{1}, \alpha_{2}\right)$ combinations $(48,30),(48,31)$. 
the minimum RMSE (0.097) is attained when $\alpha_{1}=49$ and $\alpha_{2}=29$ or 30 . If we look instead at the pooled country data, the minimum RMSE (also 0.097) is attained for roughly comparable trims from the left and right tails. ${ }^{17}$ Panels $7 \mathrm{~b}$ and $7 \mathrm{~d}$ both show that there is no gain from employing an asymmetric trim at the one-month horizon.

\section{Criteria for evaluation II: forecasting future inflation}

In this section, we look at the ability of the different core measures to forecast future headline inflation. This criterion is not entirely independent of the ability to track trend inflation. To the extent that our measure of trend reflects persistent sources of inflationary pressure, it can be seen as an "attractor" for future inflation. Thus a measure that tracks the former reasonably well ought to also help forecast future inflation. To evaluate the ability of the different measures to forecast future inflation we asked how well they detected changes in the headline HICP inflation rate eighteen months in the future. More precisely, we consider the average annual HICP inflation rate over the next eighteen months. The choice of this horizon is motivated by conventional wisdom about the lags in the monetary policy transmission process. We did not construct a formal forecasting model, as there seems little point given the short sample of data.

Figure 8 shows the root mean square forecast error (RMSFE) as a function of trim for the trimmed mean measures along with the RMSFEs for the "Ex. Energy and Seasonal Food" measure, where the RMSFE is defined as

$$
R M S F E=\sqrt{\frac{1}{T} \sum\left(\Pi_{t}^{*}-\Pi_{t+18}\right)^{2}}
$$

where $\Pi_{t}^{*}$ as before denotes our candidate core inflation measure at date $t$. That is, we evaluate the forecasting performance of the different measures in terms of their average deviation from inflation over the next eighteen months. At the most disaggregated four-digit level, the trimmed mean outperforms the traditional "Ex. Energy and Seasonal Food" measure for trims up to about $25 \%$, when pooled country data $M U(80 \times I I)$ are considered, and for any value of the trim, when area-wide average data are analysed. At the three-digit aggregation level, there is not much basis for choosing between the two measures at the MU level, while the disaggregated data suggest that the trim measure outperforms the traditional measure for most values of the trim. It must be noted that the results for trims equal to zero would correspond to a naïve forecast of no change in inflation. From this perspective, there also seems to be some gains from trimming with respect to this naïve forecast. It is also striking how similar the patterns of the RMSFEs are in this Figure to those in Figure 3, although upon reflection this should not be surprising: as argued above, a measure that does well tracking a trend defined as a 36-month centred moving average of headline inflation will probably also do reasonably well forecasting headline inflation eighteen months ahead. As in Section 4, a main caveat is the short sample on which inference is based.

Figure 9 shows the performance of these measures in real time. The two left panels show the two measures of core in real time, along with the headline inflation rate and the average annual inflation rate realised over the subsequent eighteen months. The two right panels show the deviations of the core measures from future headline inflation. Note that at the three-digit (33item) level none of the measures does particularly well. At the four-digit (80-item) level, the trimmed mean does tend to track subsequent headline inflation, and certainly does a better job than the traditional "Ex. Energy \& Seasonal Food" measure. 
Finally, Figure 10 shows the biases of the different measures in terms of their ability to forecast inflation at the eighteen-month horizon. Trimming the euro area level aggregates yields measures that on average tend to overstate subsequent headline inflation. However trimming $5 \%$ to $15 \%$ of the country level data (at either the three-digit or four-digit levels) yields better performance.

What of the ability of the Edgeworth measure to forecast future inflation? Figure II illustrates the performance of the Edgeworth measure in real time, along with current and future HICP inflation. The performance of the Edgeworth measure looks somewhat better in this Figure than it does in Figure 6. At the 33-item level of disaggregation of the HICP, the RMSFE of the Edgeworth measure is 0.335 in the MU level data and 0.696 in the pooled country data. At the 80-item level of disaggregation, the RMSFEs are 0.338 in the MU data and 0.340 in the pooled country data. Thus at all levels the Edgeworth measure is dominated by the optimally trimmed mean and the traditional "Ex. Energy and Seasonal Food" measures when it comes to forecasting future HICP inflation.

\section{Conclusions and directions for research}

The short sample of data on which this study is based mean that any conclusions must necessarily be accompanied by strong caveats. We believe that posing the question of core inflation measurement as that of detecting changes in trend inflation in real time (or forecasting headline inflation at an eighteen-month horizon) is the most sensible way to choose between competing measures of core. However, over the time period for which we have detailed information on the composition of the HICP, there have not been any major fluctuations in trend inflation, which limits the ability of this criterion to distinguish between the different measures with any degree of certainty.

With this caveat in mind, we believe that there is evidence to suggest that the trimmed mean measure of core inflation seems to outperform the traditional measures and also the Edgeworth measure. This finding is consistent with what a number of other authors have found looking at other countries and time periods. However, this result is sensitive to the choice of level of aggregation at which to characterise the cross- section distribution of price changes at a given point in time. There are two issues here: first, the choice of level of aggregation in the HICP to work with (two-digit, three-digit or four-digit); second, whether to work with euro area aggregates of the individual prices, or prices disaggregated to the country level. The superiority of the trimmed mean measure over the traditional "Ex. Energy and Seasonal Food" measure is most apparent at the four-digit level of aggregation of euro area data.

We have also shown that the trimmed mean measure dominates the Edgeworth measure which retains all price changes and simply downweights the most volatile prices. The reason for this is not immediately obvious. It may be that the sample of data we have to work with is simply too short to allow us to estimate with any degree of precision the volatility of individual prices. Alternatively it may be the case that the Edgeworth measure is inherently inferior given the backward looking nature in which it decides which prices to downweight in arriving at the core.

As for directions for future research, the short time series of the HICP (whether at the aggregate level or disaggregated level) is a major constraint on the ability of researchers to make strong recommendations about the best measure of core inflation for the euro area. It might be useful to explore ways in which the HICP time series could be extended by linking it to the national CPIs.A second possibility would be to delve more deeply into statistically robust estimators (along the lines, say, of Aucremanne (2000)), although here too the gains are likely to be small. Finally the poor performance of the Edgeworth measure is a little puzzling: a priori we would have expected that 
this measure, which discards no information, ought to at least match and ideally outperform the other measures of core. It would be worthwhile determining the exact reasons for the poor performance of the Edgeworth measure in our sample, and whether this is a general property of the measure. 


\section{References}

Aucremanne, Luc, 2000. The use of robust estimators as measures of core inflation, National Bank of Belgium, Working Paper No. 2.

Bakhshi, Hasan and Tony Yates, 1999. To trim or not to trim? An application of a trimmed mean inflation estimator to the United Kingdom, Bank of England Working Paper No. 97.

Balke, Nathan S., and Mark A. Wynne, 2000. An equilibrium analysis of relative price changes and inflation, Journal of Monetary Economics, 45, 269-292.

Ball, Laurence, and N. Gregory Mankiw, 1995. Relative price changes as aggregate supply shocks, Quarterly Journal of Economics, I10, 161-193.

Baxter, Marianne and Robert G. King, 1999. Measuring business cycles:Approximate band-pass filters for economic time series, Review of Economics and Statistics, LXXXI, 575-593.

Blinder, Alan S., 1997. Comment, Federal Reserve Bank of St. Louis Review, 79, I57-I60.

Bryan, Michael F., and Christopher J. Pike, 1991. Median price changes: An alternative approach to measuring current monetary inflation. Federal Reserve Bank of Cleveland Economic Commentary, December.

and Stephen G. Cecchetti, 1994. Measuring core inflation, in N. Gregory Mankiw (ed.) ) Monetary Policy, Chicago: University of Chicago Press.

and --, 1999a. Inflation and the distribution of price changes. es. Review of Economics and Statistics, LXXXI, I88-196.

and --, 1999b. The monthly measurement of core inflation in Japan, IMES Discussion Paper No. 99-E-4.E-4.

No. 6183.183

Cecchetti, Stephen G., 1997. Measuring short-run inflation for central bankers, Federal Reserve Bank of St. Louis Review, 79, I43-155.

Cogley, Timothy, 2000. A simple adaptive measure of core inflation, Arizona State University Department of Economics Working Paper No. 00/l4.

Diewert, W. Erwin, 1995. On the stochastic approach to index numbers, Discussion Paper No. DP 95-3I, Department of Economics University of British Columbia.

Dow, James P., Jr., 1994. Measuring inflation using multiple price indexes, unpublished manuscript, Department of Economics, University of California Riverside, June.

Freeman, Donald, 1998. Do core inflation measures help forecast inflation? Economics Letters, 58, |43-|47. 
Jaramillo, Carlos Felipe, 1998. Measuring inflation using asymmetric means, manuscript, Banco de la República, Columbia.

Kearns, Jonathan, 1998. The distribution and measurement of inflation, Reserve Bank of Australia Research Discussion Paper 9810.

Le Bihan, Hervé and Franck Sédillot, 1999. Implementing and interpreting indicators of core inflation: The French case, Banque de France Notes d'Études et de Recherche \#69.

Marques, Carlos Robalo, Pedro Duarte Neves and Luís Morais Sarmento, 2000. Evaluating core inflation indicators, Banco de Portugal WP 3-00.

Meyler, Aidan, 1999. A statistical measure of core inflation, Central Bank of Ireland Technical Paper 2/RT/99.

Monticelli, Carlo, and Luigi Buttiglione, 2000. Introducing DBCl:The Deutsche Bank measure of core inflation, Deutsche Bank Global Markets Research, February.

Quah, Danny, and Shaun P. Vahey, 1995. Measuring core inflation. Economic Journal, I05, |l30-I| 44.

Roger, Scott, 1997. A robust measure of core inflation in New Zealand, 1949-96 Reserve Bank of New Zealand Discussion Paper G97/7.

Shiratsuka, Shigenori, 1997. Inflation measures for monetary policy: Measuring the underlying inflation trend and its implication for monetary policy implementation, Bank of Japan Monetary and Economic Studies.

Vining, Daniel, and Thomas Elwertowski, 1976. The relationship between relative prices and the general price level, American Economic Review, 66, 699-708.

Wynne, Mark A., 1997. Comment, Federal Reserve Bank of St. Louis Review, 79, 161-167.

1999. Core inflation:A review of some conceptual issues, ECB Working Paper Number 5.5.

200I.The Edgeworth Index as a measure of core inflation, manuscript, Federal Reserve Bank of Dallas. 
Table I

Summary statistics for the cross-section distribution of HICP price changes

80-item (four-digit) level of disaggregation

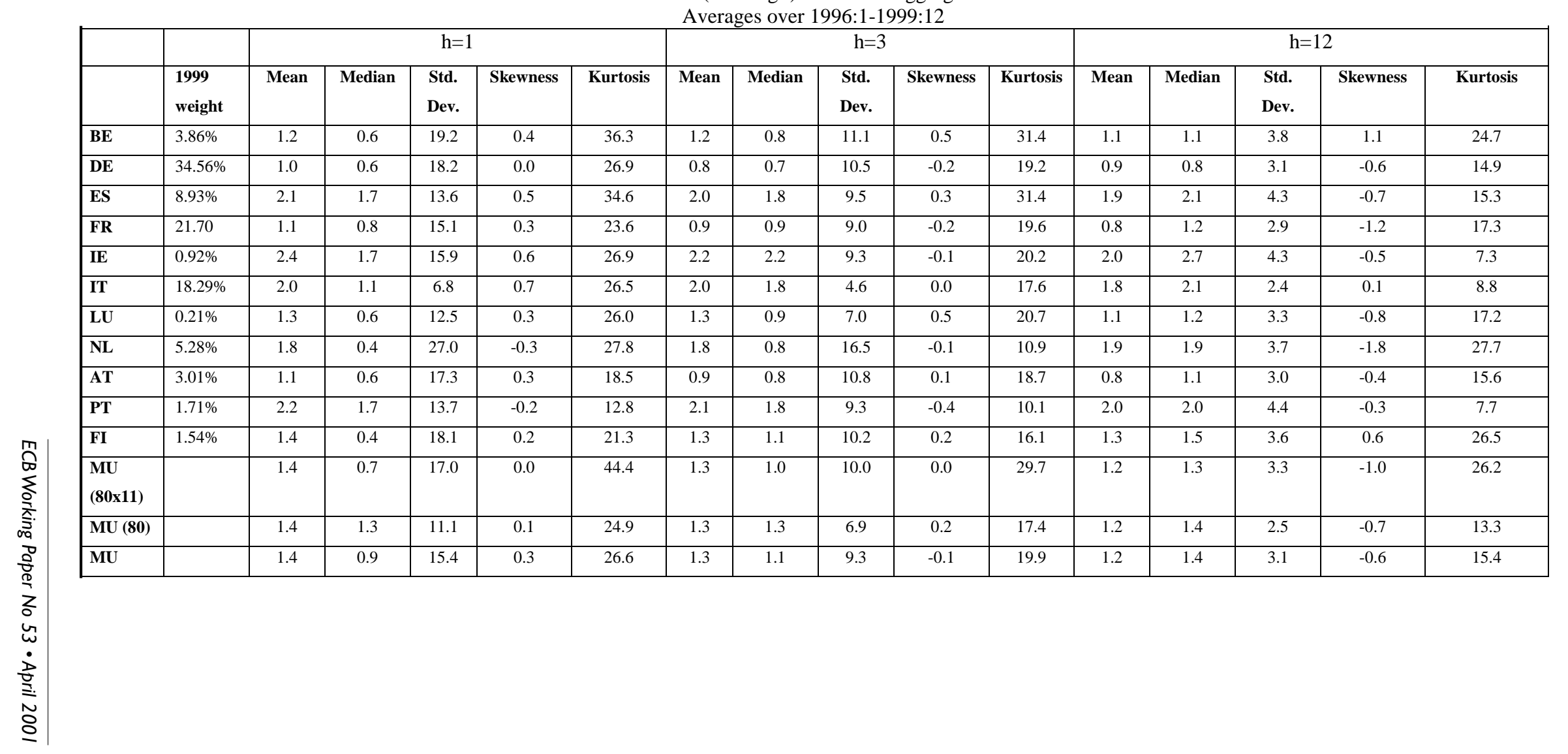


Table 2

Four-digit (80-item) disaggregation of HICP

\begin{tabular}{|c|c|c|c|c|c|c|}
\hline \multirow[t]{2}{*}{ Code } & \multicolumn{2}{|l|}{ Description } & \multicolumn{2}{|c|}{ Mean } & \multicolumn{2}{|c|}{ Standard deviation } \\
\hline & & $\begin{array}{l}1999 \\
\text { weight }\end{array}$ & $\mathrm{h}=1$ & $\mathrm{~h}=12$ & $\mathrm{~h}=1$ & $\mathrm{~h}=12$ \\
\hline 011100 & Bread and cereals & 0.029 & 1.0 & 1.0 & 0.8 & 0.1 \\
\hline 011200 & Meat & 0.046 & 0.7 & 0.2 & 3.9 & 1.6 \\
\hline 011300 & Fish & 0.013 & 2.8 & 3.6 & 11.9 & 1.6 \\
\hline 011400 & Milk; cheese and eggs & 0.024 & 0.3 & 0.2 & 1.4 & 0.3 \\
\hline 011500 & Oils and fats & 0.006 & -0.6 & -2.0 & 8.0 & 4.5 \\
\hline 011600 & Fruit & 0.013 & 1.0 & 1.5 & 23.6 & 3.3 \\
\hline 011700 & Vegetables including potatoes and other tubers & 0.018 & 0.7 & 1.7 & 38.1 & 4.2 \\
\hline 011800 & Sugar. jam; honey; syrups; chocolate and confectionery & 0.011 & 1.1 & 1.2 & 1.2 & 0.3 \\
\hline 011900 & Food products n.e.c. & 0.004 & 1.0 & 1.1 & 1.1 & 0.3 \\
\hline 012100 & Coffee; tea and cocoa & 0.006 & -0.4 & 1.0 & 10.0 & 6.9 \\
\hline 012200 & Mineral waters; soft drinks and juices & 0.010 & 0.5 & 0.5 & 1.3 & 0.3 \\
\hline 021100 & Spirits & 0.004 & 0.7 & 0.8 & 1.7 & 0.7 \\
\hline 021200 & Wine & 0.008 & 2.2 & 2.2 & 1.8 & 0.9 \\
\hline 021300 & Beer & 0.007 & 0.6 & 0.7 & 1.3 & 0.3 \\
\hline 022000 & Tobacco & 0.023 & 3.8 & 4.1 & 5.7 & 1.3 \\
\hline 031100 & Clothing materials & 0.001 & 1.7 & 1.2 & 10.1 & 0.6 \\
\hline 031200 & Garments & 0.063 & 1.4 & 0.9 & 12.0 & 0.2 \\
\hline 031300 & Other articles of clothing and clothing accessories & 0.003 & 1.4 & 1.1 & 8.8 & 0.3 \\
\hline 031400 & Dry-cleaning; repair and hire of clothing & 0.002 & 1.3 & 1.2 & 1.9 & 0.3 \\
\hline 032000 & Footwear; incl. Repairs & 0.017 & 1.8 & 1.3 & 9.7 & 0.2 \\
\hline 041000 & Actual rentals for housing & 0.066 & 2.2 & 2.2 & 1.4 & 0.5 \\
\hline 043100 & $\begin{array}{l}\text { Products for the regular maintenance and repair of the } \\
\text { dwelling }\end{array}$ & 0.009 & 1.5 & 1.5 & 1.0 & 0.3 \\
\hline 043200 & $\begin{array}{l}\text { Services for the regular maintenance and repair of the } \\
\text { dwelling }\end{array}$ & 0.011 & 1.3 & 1.7 & 3.4 & 0.7 \\
\hline 044A00 & Other services relating to the dwelling & 0.026 & 3.2 & 3.5 & 3.7 & 0.8 \\
\hline 045100 & Electricity & 0.024 & -0.6 & -0.2 & 6.8 & 0.8 \\
\hline 045200 & Gas & 0.014 & 1.5 & 1.2 & 6.7 & 4.1 \\
\hline 045300 & Liquid fuels & 0.006 & 6.7 & -0.1 & 45.8 & 15.2 \\
\hline 045400 & Solid fuels & 0.001 & 1.2 & 1.1 & 6.4 & 0.5 \\
\hline 045500 & Hot water; steam and ice & 0.005 & 1.4 & 0.0 & 6.8 & 4.8 \\
\hline 051100 & Furniture and furnishings & 0.031 & 1.2 & 1.2 & 1.7 & 0.2 \\
\hline 051200 & Carpets and other floor coverings & 0.003 & 0.6 & 0.5 & 1.4 & 0.2 \\
\hline 051300 & Repair of furniture; furnishings and floor covering & 0.001 & 2.0 & 2.0 & 1.9 & 0.4 \\
\hline 052000 & Household textiles & 0.007 & 1.3 & 1.2 & 4.3 & 0.3 \\
\hline $0531 \_2$ & $\begin{array}{l}\text { Major household appliances whether electric or not and } \\
\text { small electric household appliances }\end{array}$ & 0.011 & -0.6 & -0.6 & 0.8 & 0.2 \\
\hline 053300 & Repair of household appliances & 0.001 & 2.8 & 2.9 & 2.5 & 0.4 \\
\hline 054000 & Glassware; tableware and household utensils & 0.006 & 1.5 & 1.4 & 1.6 & 0.2 \\
\hline 055000 & Tools and equipment for house and garden & 0.005 & 0.5 & 0.5 & 0.9 & 0.2 \\
\hline 056100 & Non-durable household goods & 0.011 & 0.7 & 0.6 & 1.2 & 0.6 \\
\hline 056200 & Domestic services and home care services & 0.009 & 2.8 & 2.9 & 3.4 & 0.6 \\
\hline 06А000 & $\begin{array}{l}\text { Health - goods paid by the consumer and not } \\
\text { reimbursed }\end{array}$ & 0.008 & 3.2 & 3.5 & 4.7 & 1.0 \\
\hline 071100 & New and second-hand motorcars. & 0.046 & 0.7 & 0.5 & 3.4 & 1.0 \\
\hline $0712 \_3$ & Motor cycles and bicycles & 0.005 & 0.5 & 0.5 & 1.8 & 0.2 \\
\hline 072100 & Spares parts and accessories & 0.010 & -0.2 & -0.3 & 1.5 & 0.4 \\
\hline 072200 & Fuels and lubricants & 0.037 & 3.9 & 1.4 & 14.4 & 5.6 \\
\hline 072300 & Maintenance and repairs & 0.027 & 2.2 & 2.1 & 1.8 & 0.2 \\
\hline
\end{tabular}


Table 2 (continued)

\begin{tabular}{|c|c|c|c|c|c|c|}
\hline Code & Description & & & & Stand & tion \\
\hline 0724A0 & Other services in respect of personal transport equipment & 0.012 & 1.6 & 1.6 & 2.8 & 0.3 \\
\hline $0731 \mathrm{~A} 0$ & Passenger transport by railway & 0.005 & 1.7 & 1.9 & 4.8 & 0.5 \\
\hline $0732 \mathrm{~A} 0$ & Passenger transport by road & 0.004 & 2.3 & 2.4 & 2.3 & 0.6 \\
\hline 0733A0 & Passenger transport by air & 0.004 & 2.1 & 1.5 & 28.3 & 1.1 \\
\hline 0734A0 & Passenger transport by sea and inland waterway & 0.001 & 2.1 & 2.3 & 41.1 & 2.7 \\
\hline $0735 \mathrm{~A} 0$ & Other purchased transport services & 0.001 & 1.9 & 1.9 & 5.7 & 1.2 \\
\hline 0736A0 & Combined tickets & 0.007 & 2.6 & 2.7 & 2.6 & 0.7 \\
\hline 081100 & Postal services & 0.003 & 2.0 & 2.5 & 8.6 & 2.6 \\
\hline $0812 \_3$ & Telephone and telefax equipment and services & 0.021 & -3.1 & -3.0 & 7.9 & 1.7 \\
\hline 091100 & $\begin{array}{l}\text { Equipment for the reception. recording and reproduction of } \\
\text { sound and pictures }\end{array}$ & 0.007 & -3.9 & -3.9 & 1.7 & 0.6 \\
\hline 091200 & $\begin{array}{l}\text { Photographic and cinematographic equipment and } \\
\text { reproduction of sound and pictures }\end{array}$ & 0.001 & -3.2 & -3.2 & 1.9 & 0.6 \\
\hline 091300 & Data processing equipment & 0.003 & -9.1 & -9.3 & 4.7 & 2.3 \\
\hline 091400 & Other major durables for recreation and culture & 0.002 & 1.2 & 1.3 & 4.9 & 1.1 \\
\hline 091500 & $\begin{array}{l}\text { Games; toys and hobbies; equipment for sport; camping } \\
\text { and open-air recreation }\end{array}$ & 0.009 & 0.3 & 0.3 & 1.7 & 0.3 \\
\hline 091600 & Recording media for pictures and sound & 0.004 & -0.4 & -0.4 & 1.8 & 0.3 \\
\hline 091700 & Gardening & 0.007 & 0.8 & 1.1 & 15.3 & 0.6 \\
\hline 091800 & Pets & 0.004 & 0.3 & 0.3 & 1.4 & 0.2 \\
\hline 091900 & $\begin{array}{l}\text { Repair of equipment and accessories for recreation and } \\
\text { culture }\end{array}$ & 0.001 & 2.2 & 2.2 & 1.4 & 0.3 \\
\hline 092A00 & Recreational and cultural services & 0.027 & 2.4 & 2.6 & 4.6 & 1.2 \\
\hline 093000 & Newspaper; books and stationery & 0.023 & 2.0 & 1.9 & 1.8 & 0.4 \\
\hline 094000 & Package holidays & 0.012 & 3.7 & 2.1 & 62.1 & 1.5 \\
\hline 10A000 & $\begin{array}{l}\text { Education - commonly paid by consumers in Member } \\
\text { States }\end{array}$ & 0.004 & 2.4 & 2.4 & 3.1 & 0.2 \\
\hline 111100 & Restaurants and cafés & 0.061 & 2.0 & 2.0 & 0.8 & 0.1 \\
\hline 111200 & Canteens & 0.008 & 2.0 & 2.0 & 2.2 & 0.4 \\
\hline 112000 & Accommodation services & 0.014 & 2.8 & 2.8 & 22.1 & 0.5 \\
\hline 121100 & Hairdressing salons and personal grooming establishments & 0.013 & 2.2 & 2.3 & 1.3 & 0.3 \\
\hline 121200 & Appliances. articles and products for personal care & 0.017 & 1.1 & 1.1 & 1.3 & 0.2 \\
\hline 122000 & Personal effects n.e.c. & 0.011 & 0.2 & 0.0 & 1.9 & 0.2 \\
\hline $1242 \mathrm{~A} 0$ & $\begin{array}{l}\text { Insurance connected with the dwelling - Contents } \\
\text { insurance }\end{array}$ & 0.003 & 0.4 & 0.3 & 1.5 & 0.4 \\
\hline $1244 \mathrm{~A} 0$ & Insurance connected with transport - car insurance & 0.006 & 1.7 & 1.2 & 7.1 & 3.3 \\
\hline $125 \mathrm{~A} 00$ & Banking services n.e.c. & 0.005 & 2.0 & 2.1 & 4.6 & 0.8 \\
\hline $126 \mathrm{~A} 00$ & Other services n.e.c. & 0.009 & 2.0 & 1.9 & 3.5 & 1.0 \\
\hline
\end{tabular}


Table 3

Definition of exclusion-type measures of core inflation

\begin{tabular}{|l|l|}
\hline \multicolumn{1}{|c|}{ Measure } & \multicolumn{1}{|c|}{ Price excluded at the four-digit level } \\
\hline Excluding energy & $0451,0452,0453,0454,0455,0722$ \\
\hline Excluding seasonal food & $0113,0116,0117$ \\
\hline Excluding energy and food & $0112,0113,0116,0117,0451,0452,0453,0454,0455,0722$ \\
\hline Excluding energy and seasonal food & $0113,0116,0117,0451,0452,0453,0454,0455,0722$ \\
\hline $\begin{array}{l}\text { Excluding energy and unprocessed } \\
\text { food }\end{array}$ & $0112,0113,0116,0117,0451,0452,0453,0454,0455,0722$ \\
\hline $\begin{array}{l}\text { Excluding alcoholic beverages and } \\
\text { tobacco }\end{array}$ & $0211,0212,0213,0220$ \\
\hline $\begin{array}{l}\text { Excluding energy, food, alcohol and } \\
\text { tobacco }\end{array}$ & $0113,0116,0117,0211,0212,0213,0220,0451,0452,0453$, \\
\hline $\begin{array}{l}\text { Excluding housing, water, electricity, } \\
\text { gas and other fuels }\end{array}$ & $\begin{array}{l}0410,0431,0432,044 \mathrm{~A}, 0451,0452,0453,0454,0455,0511, \\
0512,0513,0531 \_2,0533\end{array}$ \\
\hline $\begin{array}{l}\text { Excluding education health and social } \\
\text { protection }\end{array}$ & $0611,0612 \_3,0621 \_3,0622,0630,10 \mathrm{X} 0,1240$ \\
\hline $\begin{array}{l}\text { Excluding liquid fuels and fuels and } \\
\text { lubricants for personal transport } \\
\text { equipment }\end{array}$ & 0453,0722 \\
\hline
\end{tabular}

\section{Table 4}

Comparison of traditional exclusion-type measures of core and trimmed mean

\begin{tabular}{|l|c|c|}
\hline & RMSE & Bias \\
\hline All items excluding alcoholic beverages and tobacco & 0.2551 & 0.03 \\
\hline All items excluding energy & 0.3218 & 0.22 \\
\hline All items excluding education, health and social protection & 0.2580 & 0.08 \\
\hline All items excluding energy and food & 0.2441 & 0.20 \\
\hline All items excluding energy and unprocessed food & 0.2426 & 0.19 \\
\hline All items excluding energy and seasonal food & 0.2155 & 0.17 \\
\hline All items excluding liquid fuels and fuels and lubricants for & 0.2929 & 0.20 \\
personal transport equipment & & 0.00 \\
\hline All items excluding housing, water, electricity, gas and other fuels & 0.2235 & 0.06 \\
\hline All items excluding seasonal food & 0.2715 & 0.02 \\
\hline Trimmed mean (optimal) & 0.0698 & \\
\hline
\end{tabular}


Table 5

Frequency with which individual items are excluded by trimming

\begin{tabular}{|c|c|c|c|c|c|}
\hline Code & Description & \begin{tabular}{|c|}
$\begin{array}{c}\text { Excluded } \\
\text { from } \\
\text { bottom of } \\
\text { distribution }\end{array}$ \\
\end{tabular} & \begin{tabular}{|c|} 
Excluded \\
from top of \\
distribution \\
\end{tabular} & \begin{tabular}{|l|} 
Excluded \\
\end{tabular} & Included \\
\hline 011100 & Bread and cereals & \begin{tabular}{|l|}
4.3 \\
\end{tabular} & 10.6 & 14.9 & 85.1 \\
\hline 011200 & Meat & 46.8 & 36.2 & 83.0 & 17.0 \\
\hline 011300 & Fish & 34.0 & 53.2 & 87.2 & 12.8 \\
\hline 011400 & Milk; cheese and eggs & 51.1 & 8.5 & 59.6 & 40.4 \\
\hline 011500 & Oils and fats & 59.6 & 25.5 & 85.1 & 14.9 \\
\hline 011600 & Fruit & 46.8 & 48.9 & 95.7 & 4.3 \\
\hline 011700 & Vegetables including potatoes and other tubers & 40.4 & 51.1 & 91.5 & 8.5 \\
\hline 011800 & Sugar. jam; honey; syrups; chocolate and confectionery & 19.1 & 8.5 & 27.7 & 72.3 \\
\hline 011900 & Food products n.e.c. & 29.8 & 14.9 & 44.7 & 55.3 \\
\hline 012100 & Coffee; tea and cocoa & 74.5 & 19.1 & 93.6 & 6.4 \\
\hline 012200 & Mineral waters; soft drinks and juices & 38.3 & 6.4 & 44.7 & 55.3 \\
\hline 021100 & Spirits & 44.7 & 10.6 & 55.3 & 44.7 \\
\hline 021200 & Wine & 17.0 & 42.6 & 59.6 & 40.4 \\
\hline 021300 & Beer & 40.4 & 14.9 & 55.3 & 44.7 \\
\hline 022000 & \begin{tabular}{|l|} 
Tobacco \\
\end{tabular} & 21.3 & 29.8 & 51.1 & 48.9 \\
\hline 031100 & Clothing materials & 48.9 & 42.6 & 91.5 & 8.5 \\
\hline 031200 & Garments & 34.0 & 53.2 & 87.2 & 12.8 \\
\hline 031300 & Other articles of clothing and clothing accessories & 29.8 & 42.6 & 72.3 & 27.7 \\
\hline 031400 & Dry-cleaning; repair and hire of clothing & 23.4 & 14.9 & 38.3 & 61.7 \\
\hline 032000 & Footwear; incl. repairs & 31.9 & 55.3 & 87.2 & 12.8 \\
\hline 041000 & Actual rentals for housing & 0.0 & 27.7 & 27.7 & 72.3 \\
\hline 043100 & Products for the regular maintenance and repair of the dwelling & 8.5 & 14.9 & 23.4 & 76.6 \\
\hline 043200 & Services for the regular maintenance and repair of the dwelling & 12.8 & 25.5 & 38.3 & 61.7 \\
\hline $044 \mathrm{~A} 00$ & Other services relating to the dwelling & 10.6 & 46.8 & 57.4 & 42.6 \\
\hline 045100 & Electricity & 44.7 & 8.5 & 53.2 & 46.8 \\
\hline 045200 & Gas & 42.6 & 42.6 & 85.1 & 14.9 \\
\hline 045300 & Liquid fuels & 46.8 & 53.2 & 100.0 & 0.0 \\
\hline 045400 & Solid fuels & 34.0 & 46.8 & 80.9 & 19.1 \\
\hline 045500 & Hot water; steam and ice & 36.2 & 48.9 & 85.1 & 14.9 \\
\hline 051100 & Furniture and furnishings & 4.3 & 27.7 & 31.9 & 68.1 \\
\hline 051200 & Carpets and other floor coverings & 25.5 & 14.9 & 40.4 & 59.6 \\
\hline 051300 & Repair of furniture; furnishings and floor covering & 6.4 & 34.0 & 40.4 & 59.6 \\
\hline 052000 & Household textiles & 25.5 & 34.0 & 59.6 & 40.4 \\
\hline $0531 \_2$ & $\begin{array}{l}\text { Major household appliances whether electric or not and small electric } \\
\text { household appliances }\end{array}$ & 63.8 & 0.0 & 63.8 & 36.2 \\
\hline 053300 & Repair of household appliances & 2.1 & 38.3 & 40.4 & 59.6 \\
\hline 054000 & Glassware; tableware and household utensils & 10.6 & 19.1 & 29.8 & 70.2 \\
\hline 055000 & Tools and equipment for house and garden & 17.0 & 10.6 & 27.7 & 72.3 \\
\hline 056100 & Non-durable household goods & 14.9 & 14.9 & 29.8 & 70.2 \\
\hline 056200 & Domestic services and home care services & 6.4 & 29.8 & 36.2 & 63.8 \\
\hline 06А000 & Health - goods paid by the consumer and not reimbursed & 4.3 & 29.8 & 34.0 & 66.0 \\
\hline 071100 & New and second-hand motorcars & 25.5 & 27.7 & 53.2 & 46.8 \\
\hline $0712 \_3$ & Motor cycles and bicycles & 29.8 & 17.0 & 46.8 & 53.2 \\
\hline 072100 & Spares parts and accessories & 59.6 & 8.5 & 68.1 & 31.9 \\
\hline 072200 & Fuels and lubricants & 48.9 & 40.4 & 89.4 & 10.6 \\
\hline 072300 & Maintenance and repairs & 2.1 & 34.0 & 36.2 & 63.8 \\
\hline 0724A0 & Other services in respect of personal transport equipment & 10.6 & 21.3 & 31.9 & 68.1 \\
\hline $0731 \mathrm{~A} 0$ & Passenger transport by railway & 31.9 & 25.5 & 57.4 & 42.6 \\
\hline 0732A0 & Passenger transport by road & 6.4 & 29.8 & 36.2 & 63.8 \\
\hline 0733A0 & Passenger transport by air & 48.9 & 42.6 & 91.5 & 8.5 \\
\hline $0734 \mathrm{~A} 0$ & Passenger transport by sea and inland waterway & 40.4 & 46.8 & 87.2 & 12.8 \\
\hline $0735 \mathrm{~A} 0$ & Other purchased transport services & 31.9 & 40.4 & 72.3 & 27.7 \\
\hline 0736A0 & Combined tickets & 12.8 & 29.8 & 42.6 & 57.4 \\
\hline 081100 & Postal services & 38.3 & 21.3 & 59.6 & 40.4 \\
\hline $0812 \_3$ & Telephone and telefax equipment and services & 68.1 & 10.6 & 78.7 & 21.3 \\
\hline 091100 & $\begin{array}{l}\text { Equipment for the reception. recording and } \\
\text { Reproduction of sound and pictures }\end{array}$ & 100.0 & 0.0 & 100.0 & 0.0 \\
\hline
\end{tabular}


Table 5 (continued)

\begin{tabular}{|c|c|c|c|c|c|}
\hline 091200 & $\begin{array}{l}\text { Photographic and cinematographic equipment and } \\
\text { Reproduction of sound and pictures }\end{array}$ & 95.7 & 0.0 & 95.7 & 4.3 \\
\hline 091300 & Data processing equipment & 100.0 & 0.0 & 100.0 & 0.0 \\
\hline 091400 & Other major durables for recreation and culture & 34.0 & 12.8 & 46.8 & 53.2 \\
\hline 091500 & $\begin{array}{l}\text { Games; toys and hobbies; equipment for sport; camping and open-air } \\
\text { recreation }\end{array}$ & 27.7 & 12.8 & 40.4 & 59.6 \\
\hline 091600 & Recording media for pictures and sound & 53.2 & 6.4 & 59.6 & 40.4 \\
\hline 091700 & Gardening & 48.9 & 51.1 & 100.0 & 0.0 \\
\hline 091800 & Pets & 40.4 & 17.0 & 57.4 & 42.6 \\
\hline 091900 & Repair of equipment and accessories for recreation and culture & 6.4 & 31.9 & 38.3 & 61.7 \\
\hline $092 \mathrm{~A} 00$ & Recreational and cultural services & 17.0 & 29.8 & 46.8 & 53.2 \\
\hline 093000 & Newspaper; books and stationery & 6.4 & 31.9 & 38.3 & 61.7 \\
\hline 094000 & Package holidays & 44.7 & 53.2 & 97.9 & 2.1 \\
\hline 10A000 & Education - commonly paid by consumers in Member States & 21.3 & 29.8 & 51.1 & 48.9 \\
\hline 111100 & Restaurants and cafés & 2.1 & 21.3 & 23.4 & 76.6 \\
\hline 111200 & Canteens & 21.3 & 31.9 & 53.2 & 46.8 \\
\hline 112000 & Accommodation services & 36.2 & 53.2 & 89.4 & 10.6 \\
\hline 121100 & Hairdressing salons and personal grooming establishments & 2.1 & 29.8 & 31.9 & 68.1 \\
\hline 121200 & Appliances. articles and products for personal care & 17.0 & 17.0 & 34.0 & 66.0 \\
\hline 122000 & Personal effects n.e.c. & 31.9 & 14.9 & 46.8 & 53.2 \\
\hline $1242 \mathrm{~A} 0$ & Insurance connected with the dwelling - Contents insurance & 40.4 & 6.4 & 46.8 & 53.2 \\
\hline $1244 \mathrm{~A} 0$ & Insurance connected with transport - car insurance & 23.4 & 25.5 & 48.9 & 51.1 \\
\hline $125 \mathrm{~A} 00$ & Banking services n.e.c. & 29.8 & 23.4 & 53.2 & 46.8 \\
\hline $126 \mathrm{~A} 00$ & Other services n.e.c. & 12.8 & 29.8 & 42.6 & 57.4 \\
\hline
\end{tabular}




\section{Figure I}

Euro area inflation 1990-2000

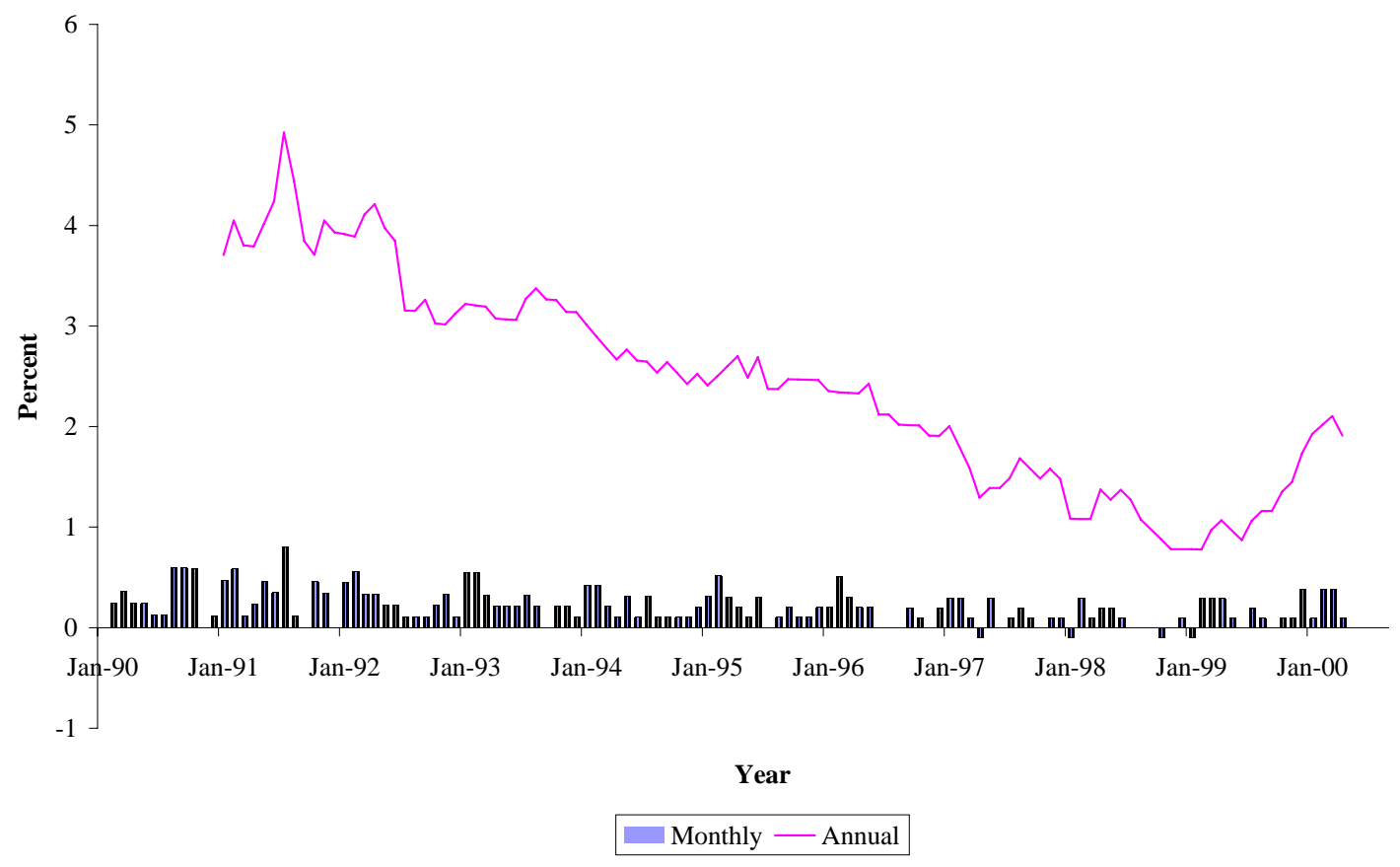




\section{Figure 2}

Summary statistics for the cross-section distribution of price changes: 80-item (four digit) level
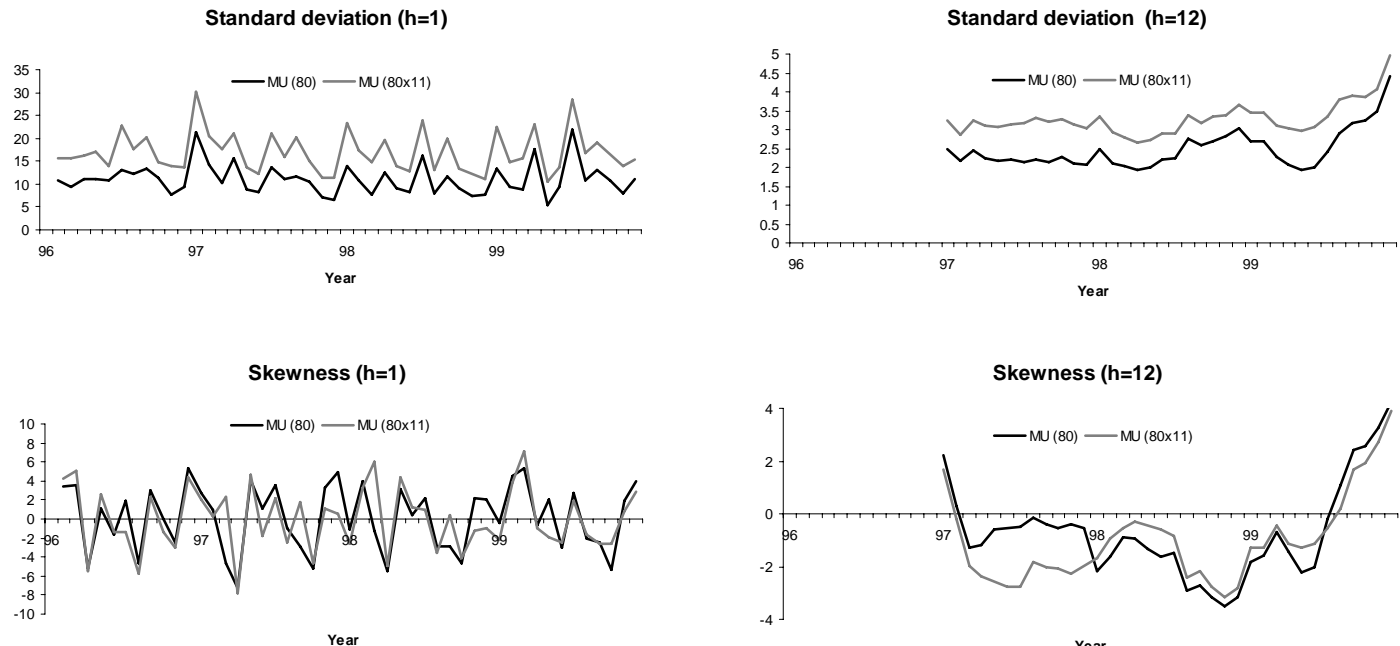

Kurtosis $(\mathrm{h}=1)$

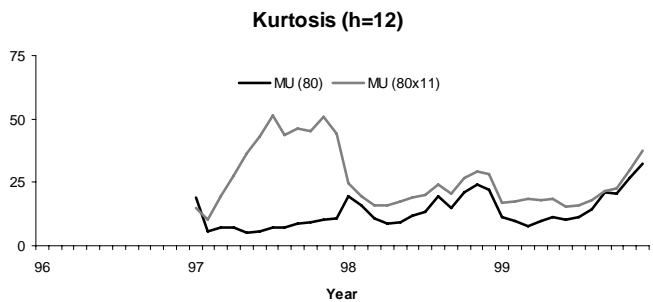

\section{Figure 3}

Tracking trend inflation: RMSE as a function of trim 1997: 1-1998:11
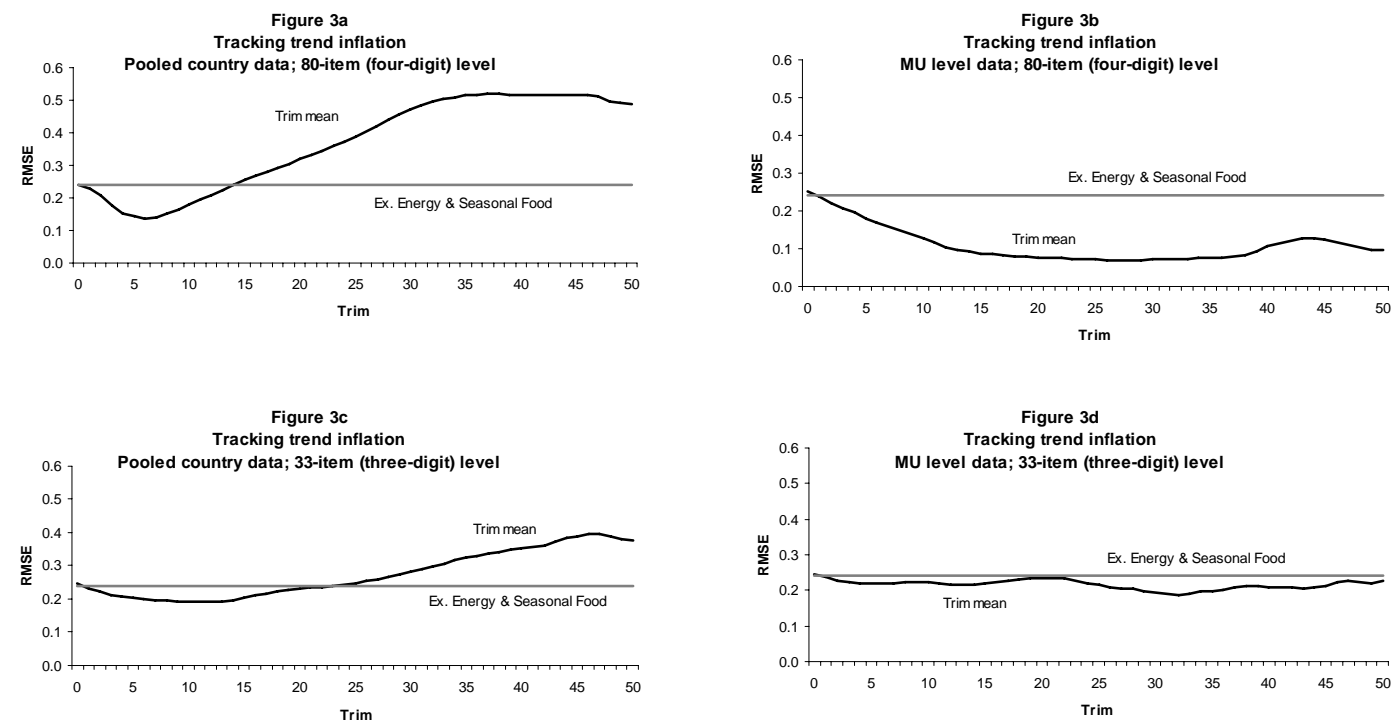


\section{Figure 4}

Tracking trend inflation in real time

Figure 4a

Tracking trend; 33-item (three-digit) level

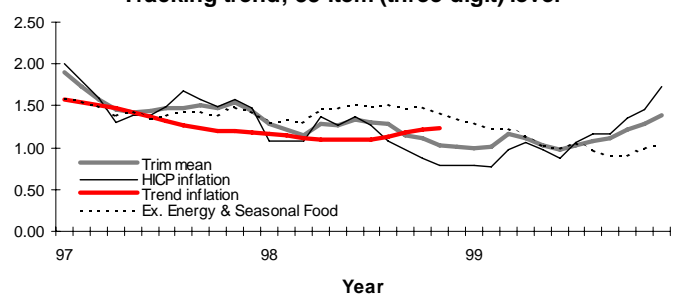

Figure 4c

Tracking trend; 80-item (four-digit) leve

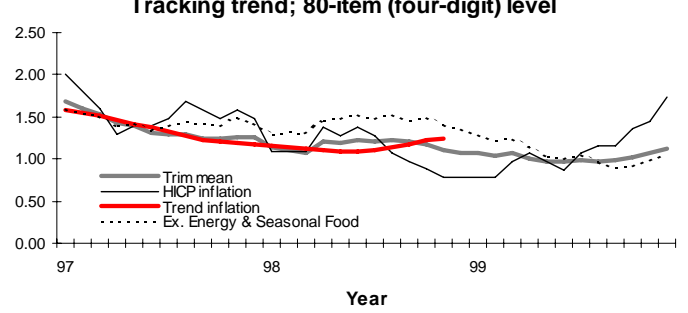

Figure $4 \mathrm{~b}$

Deviation from trend; 33-item (three-digit) leve

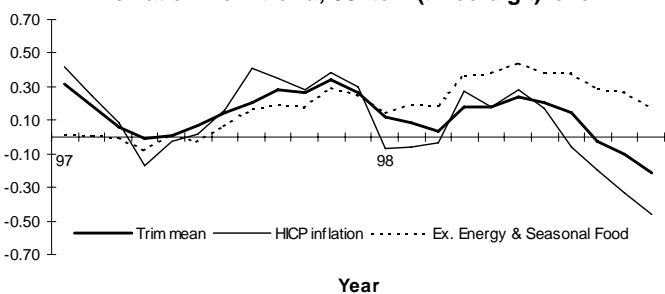

Figure 4d

Deviation from trend; 80 -item (four-digit) level

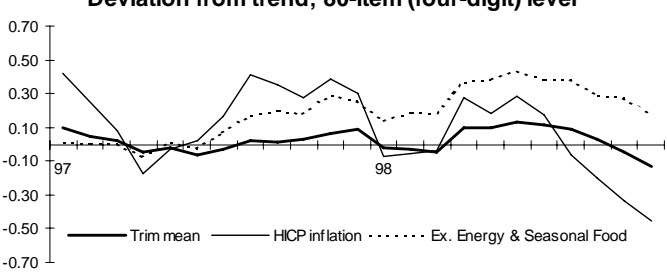

Year

Figure 5

Bias in tracking trend
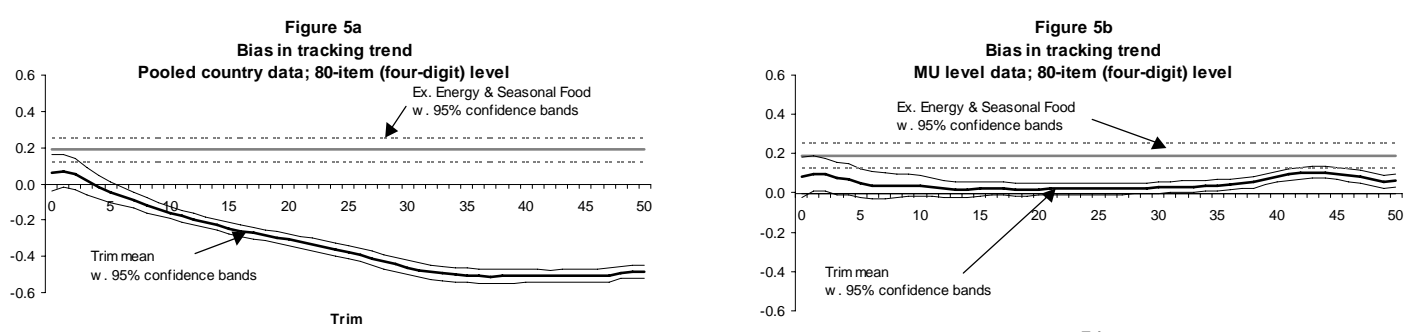

Figure $5 \mathrm{c}$

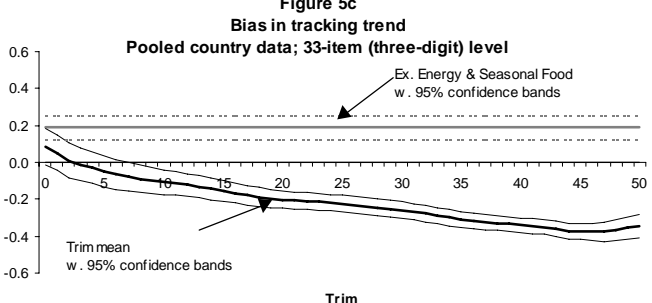

Trim

Figure $5 d$

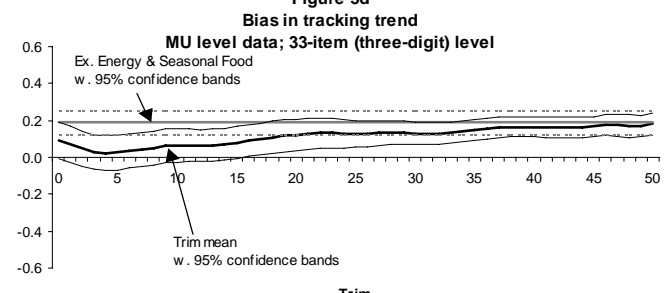




\section{Figure 6}

Tracking trend inflation in real time

Figure 6a

Edgew orth index and trend inflation
MU level data; 33 -item (three-digit) level; $h=1$

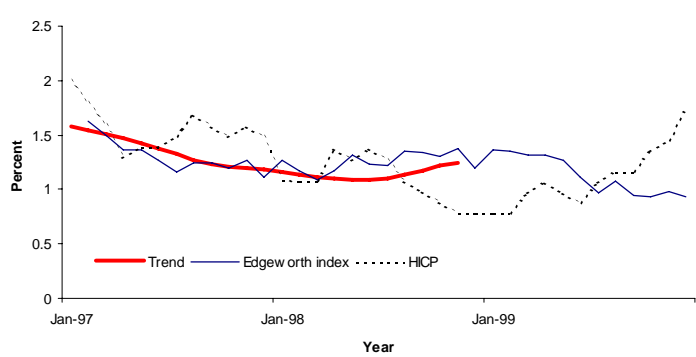

Figure $6 c$

MU level data; 80 -item (four-digit) level; $h=1$

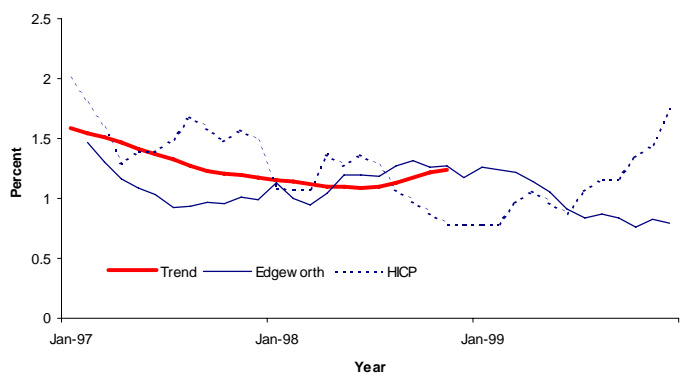

Figure $6 \mathrm{~b}$
Edgew orth index and trend inflation Pooled country data; 33 -item (three-digit) level; $h=1$

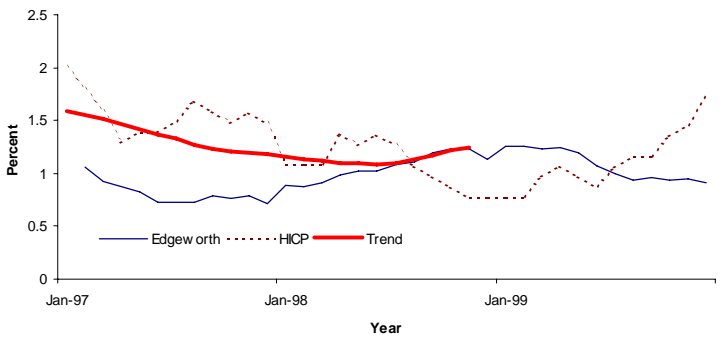

Figure 60 Pooled chewrith index and rend inflation

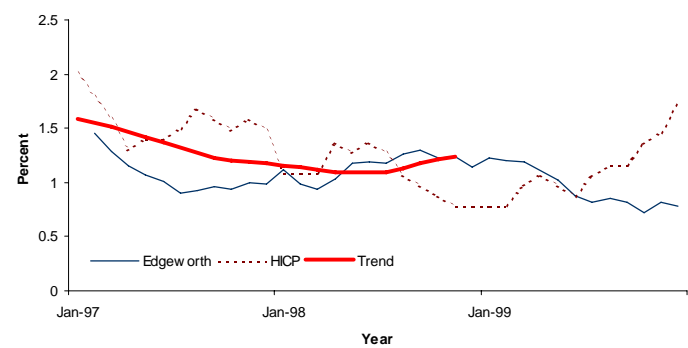




\section{Figure 7}

RMSE as a function of trim for asymmetric trims

Figure 7a

RMSE as a function of trim

$h=12 ; 80$-item (four-digit) level

MU level data

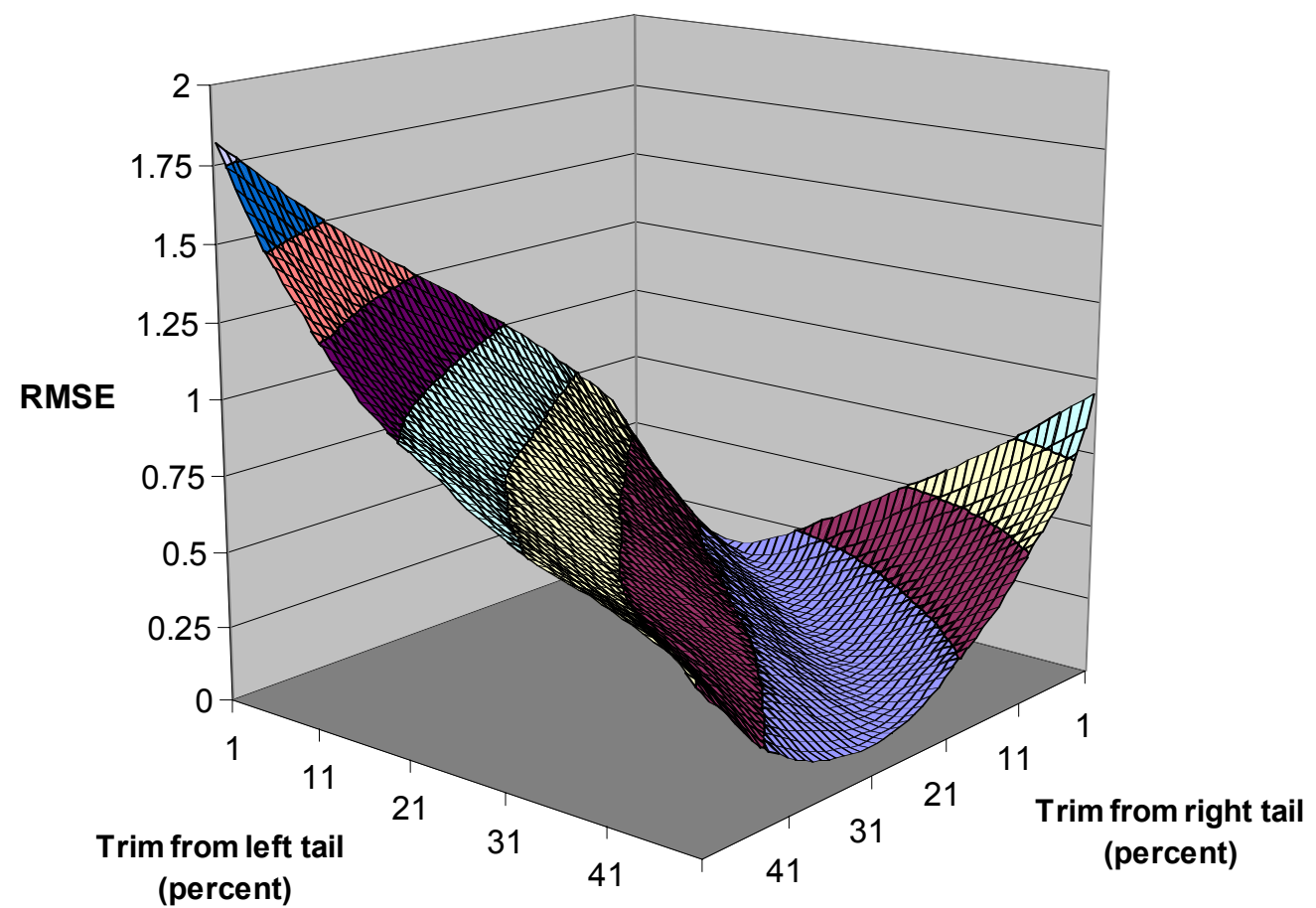




\section{Figure 7 (continued)}

RMSE as a function of trim for asymmetric trims

Figure 7b

RMSE as a function of trim

$h=1$ (compounded); 80-item (four-digit) level

MU level data

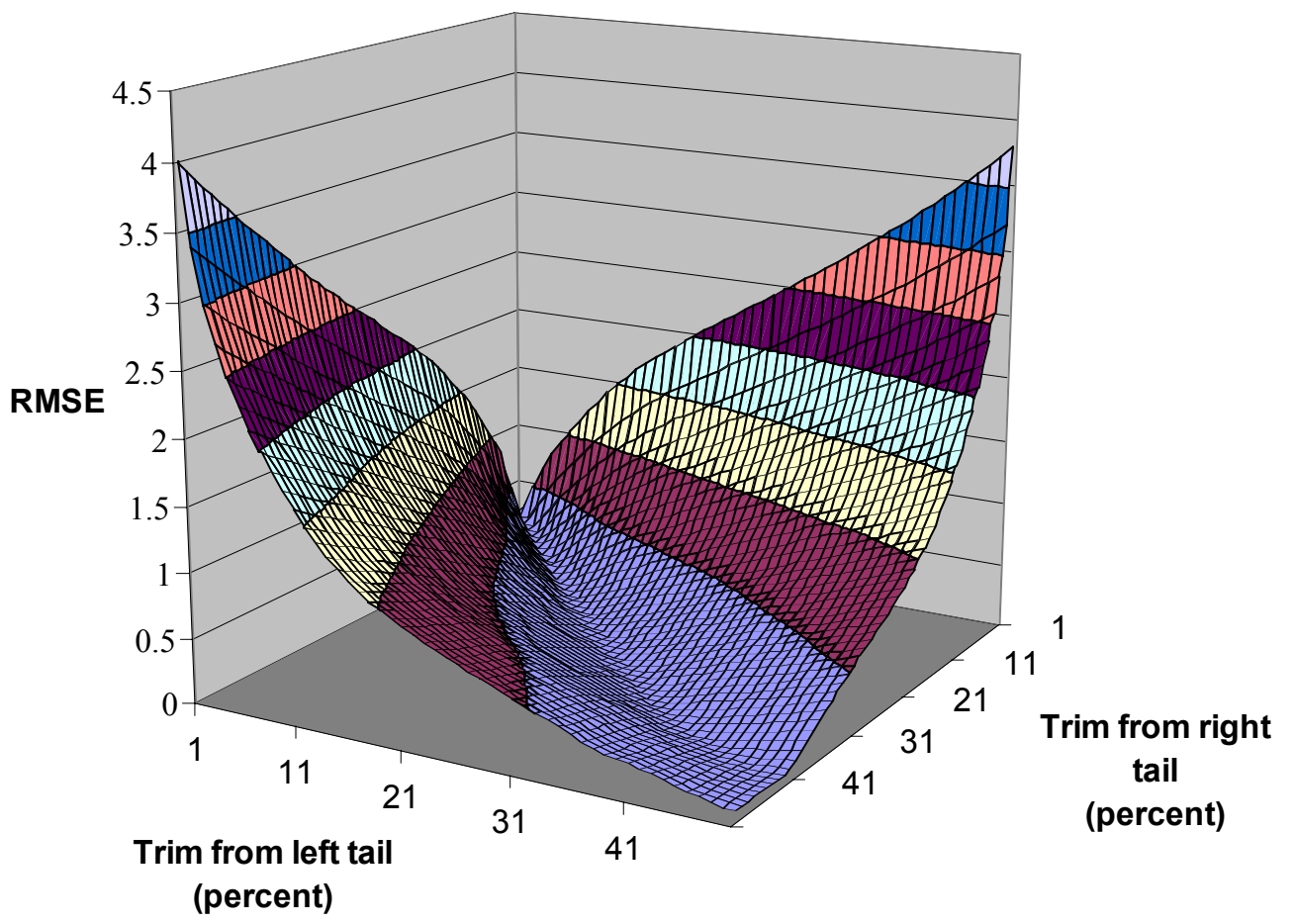




\section{Figure 7 (continued)}

RMSE as a function of trim for asymmetric trims

Figure 7c

RMSE as a function of trim

$h=12 ; 80$-item (four-digit) level

Pooled country data

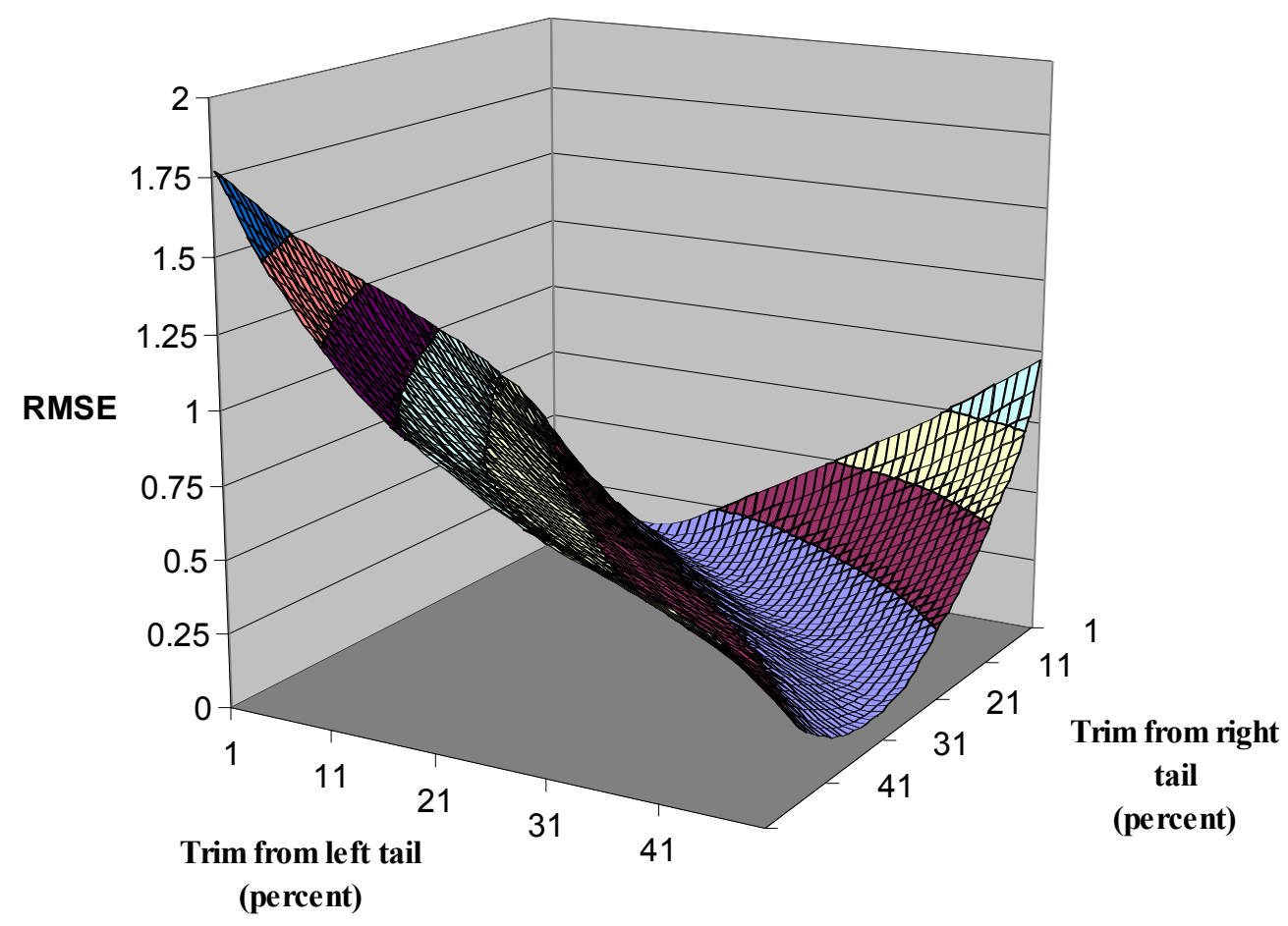




\section{Figure 7 (continued)}

RMSE as a function of trim for asymmetric trims

Figure 7d

RMSE as a function of trim

$h=1$ (compounded); 80-item (four-digit) level

Pooled country data

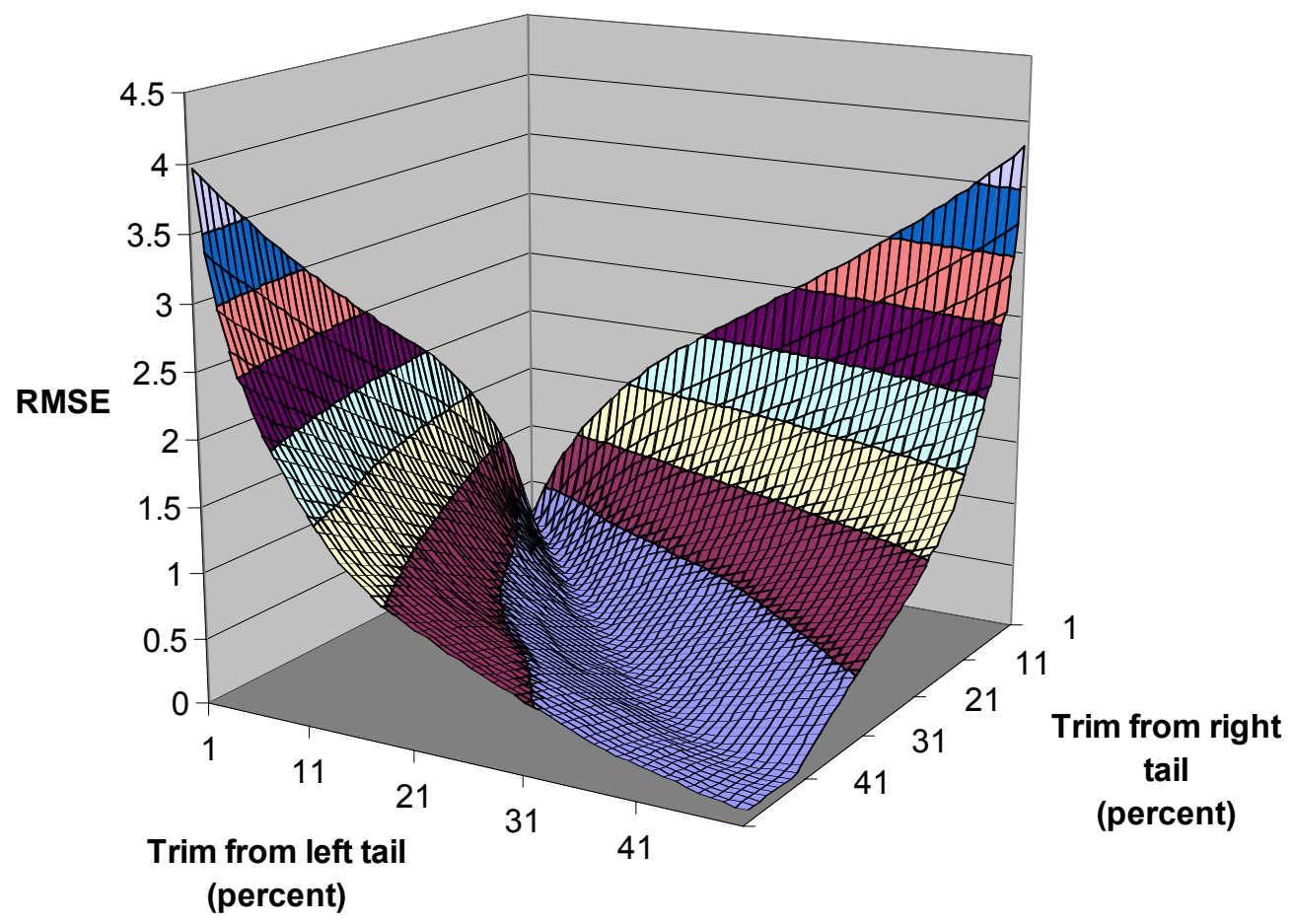




\section{Figure 8}

Forecasting inflation at an 18-month horizon: RMSFE as a function of trim 1997:1-1998:11
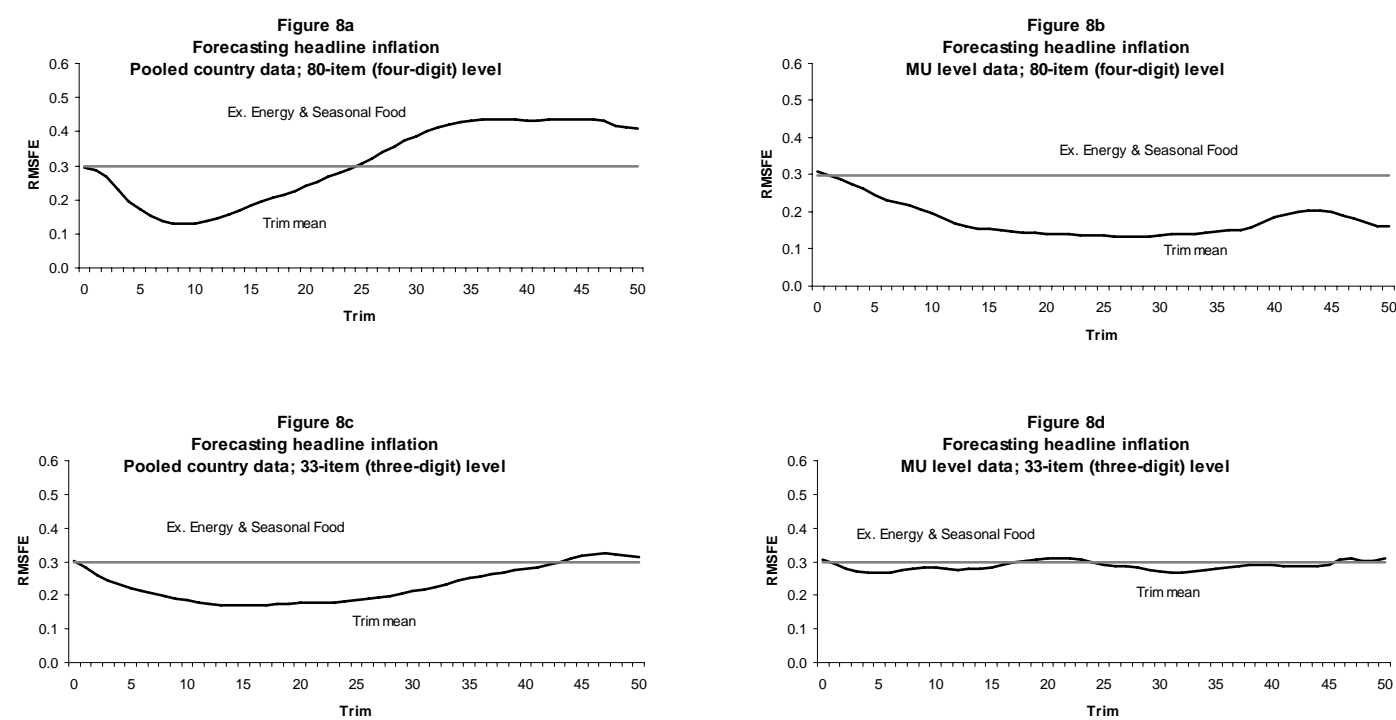

\section{Figure 9}

Forecasting inflation at an 18-month horizon
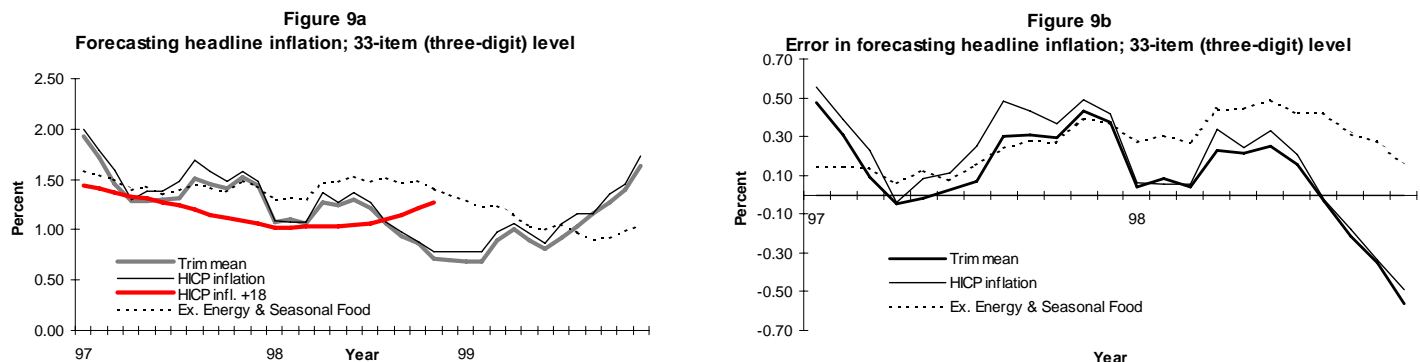

Figure 9c

Forecasting headline inflation; 80 -item (four-digit) level

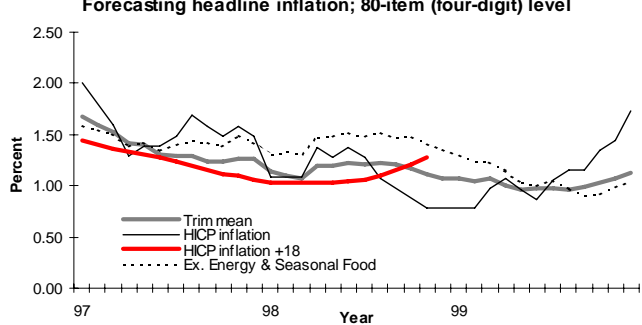

Figure 9d

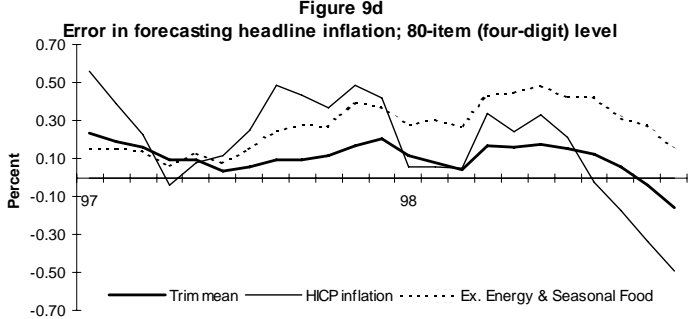

Year 


\section{Figure 10}

Bias in inflation forecasts at an 18-month horizon
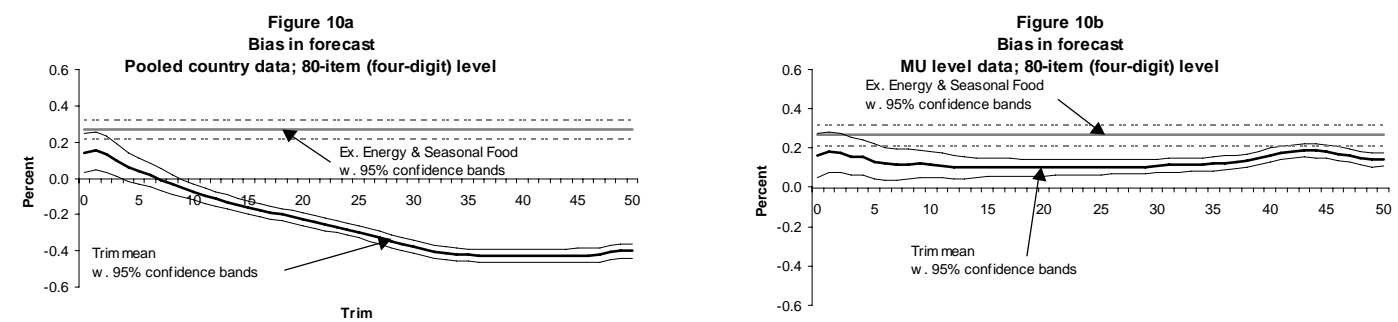

Figure 10c
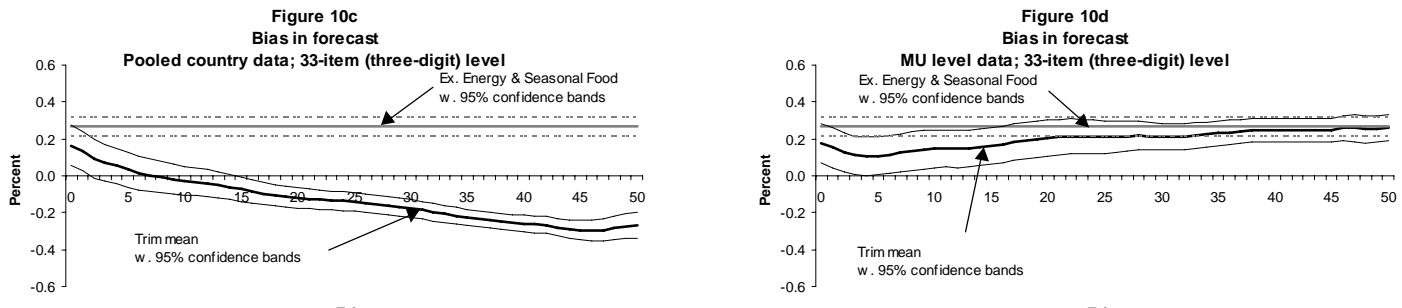

Trim

Trim

\section{Figure I I}

Forecasting inflation at an 18-month horizon
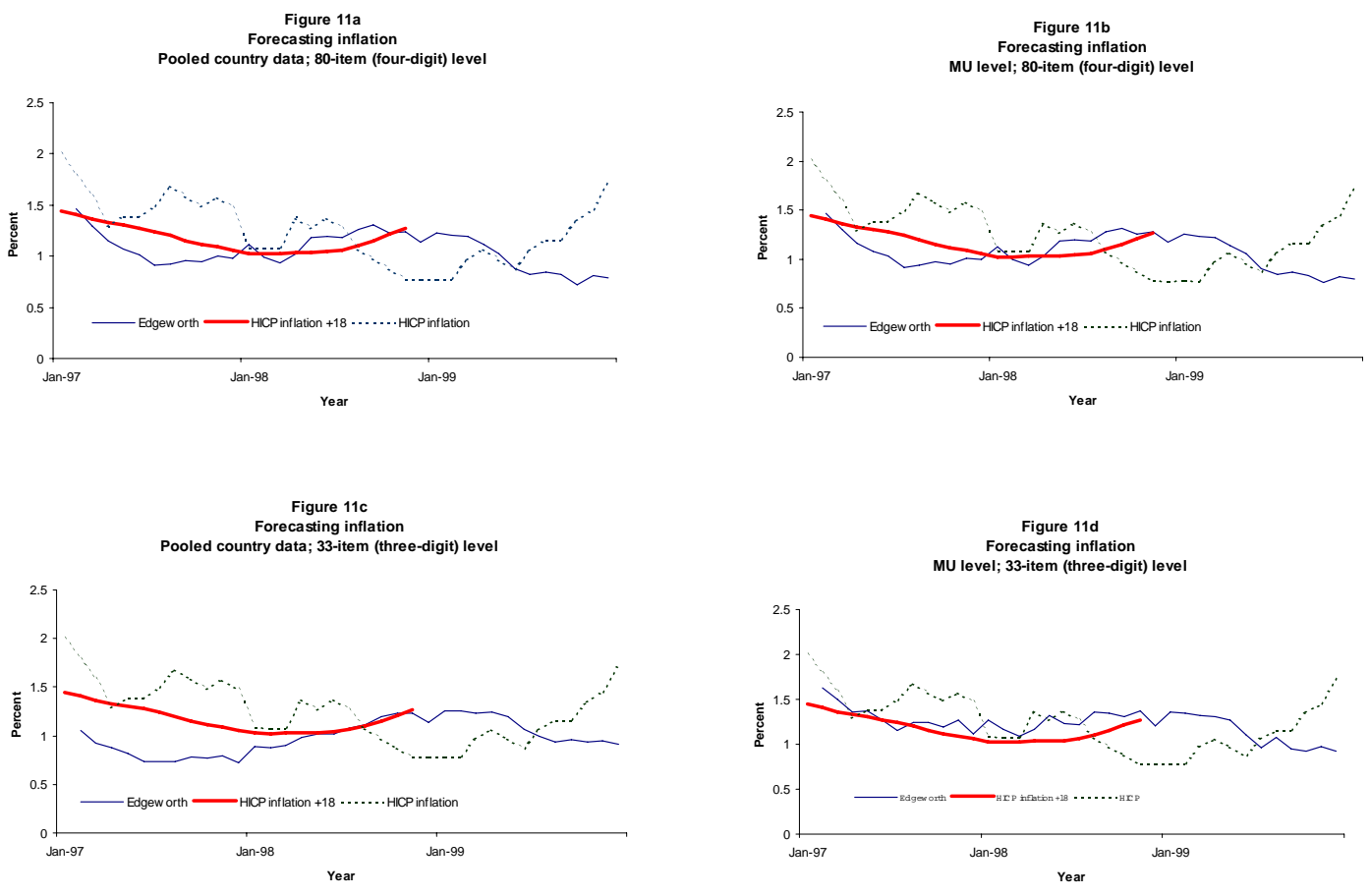


\section{European Central Bank Working Paper Series}

I "A global hazard index for the world foreign exchange markets" by V. Brousseau and F. Scacciavillani, May 1999.

2 "What does the single monetary policy do? A SVAR benchmark for the European Central Bank" by C. Monticelli and O.Tristani, May 1999.

3 "Fiscal policy effectiveness and neutrality results in a non-Ricardian world" by C. Detken, May 1999.

4 "From the ERM to the euro: new evidence on economic and policy convergence among EU countries” by I.Angeloni and L. Dedola, May 1999.

5 “Core inflation: a review of some conceptual issues” by M.Wynne, May 1999.

6 "The demand for M3 in the euro area" by G. Coenen and J.-L.Vega, September 1999.

7 “A cross-country comparison of market structures in European banking” by O. de Bandt and E. P. Davis, September 1999.

8 “Inflation zone targeting" by A. Orphanides and V.Wieland, October 1999.

9 "Asymptotic confidence bands for the estimated autocovariance and autocorrelation functions of vector autoregressive models" by G. Coenen, January 2000.

10 "On the effectiveness of sterilized foreign exchange intervention" by R. Fatum, February 2000.

II "Is the yield curve a useful information variable for the Eurosystem?" by J. M. Berk and P. van Bergeijk, February 2000.

I2 "Indicator variables for optimal policy" by L. E. O. Svensson and M. Woodford, February 2000.

I3 “Monetary policy with uncertain parameters” by U. Söderström, February 2000.

I4 "Assessing nominal income rules for monetary policy with model and data uncertainty" by G. D. Rudebusch, February 2000.

15 “The quest for prosperity without inflation” by A. Orphanides, March 2000.

I6 "Estimating the implied distribution of the future short term interest rate using the Longstaff-Schwartz model” by P. Hördahl, March 2000.

17 "Alternative measures of the NAIRU in the euro area: estimates and assessment" by S. Fabiani and R. Mestre, March 2000.

I8 "House prices and the macroeconomy in Europe: Results from a structural VAR analysis" by M. lacoviello, April 2000. 
19 "The euro and international capital markets" by C. Detken and P. Hartmann, April 2000.

20 "Convergence of fiscal policies in the euro area" by O. De Bandt and F. P. Mongelli, May 2000.

21 "Firm size and monetary policy transmission: evidence from German business survey data" by M. Ehrmann, May 2000.

22 "Regulating access to international large value payment systems" by C. Holthausen and T. Rønde, June 2000.

23 “Escaping Nash inflation” by In-Koo Cho and T. J. Sargent, June 2000.

24 "What horizon for price stability" by F. Smets, July 2000.

25 "Caution and conservatism in the making of monetary policy" by P. Schellekens, July 2000.

26 "Which kind of transparency? On the need for clarity in monetary policy-making" by B.Winkler, August 2000.

27 "This is what the US leading indicators lead" by M. Camacho and G. Perez-Quiros, August 2000.

28 "Learning, uncertainty and central bank activism in an economy with strategic interactions" by M. Ellison and N.Valla, August 2000.

29 "The sources of unemployment fluctuations: an empirical application to the Italian case" by S. Fabiani, A. Locarno, G. Oneto and P. Sestito, September 2000.

30 "A small estimated euro area model with rational expectations and nominal rigidities" by G. Coenen and V. Wieland, September 2000.

31 "The disappearing tax base: Is foreign direct investment eroding corporate income taxes?" by R. Gropp and K. Kostial, September 2000.

32 "Can indeterminacy explain the short-run non-neutrality of money?" by F. De Fiore, September 2000.

33 "The information content of M3 for future inflation" by C. Trecroci and J. L. Vega, October 2000.

34 "Capital market development, corporate governance and the credibility of exchange rate pegs” by O. Castrén and T.Takalo, October 2000.

35 “Systemic risk: A survey” by O. De Bandt and P. Hartmann, November 2000.

36 "Measuring core inflation in the euro area" by C. Morana, November 2000.

37 "Business fixed investment: Evidence of a financial accelerator in Europe" by P.Vermeulen, November 2000. 
38 "The optimal inflation tax when taxes are costly to collect" by F. De Fiore, November 2000.

39 “A money demand system for euro area M3" by C. Brand and N. Cassola, November 2000.

40 "Financial structure and the interest rate channel of ECB monetary policy" by B. Mojon, November 2000.

4I "Why adopt transparency? The publication of central bank forecasts" by P. M. Geraats, January 200I.

42 "An area-wide model (AWM) for the euro area" by G. Fagan, J. Henry and R. Mestre, January 2001 .

43 "Sources of economic renewal: from the traditional firm to the knowledge firm" by D. R. Palenzuela, February 2001.

44 "The supply and demand for eurosystem deposits - The first 18 months" by U. Bindseil and F. Seitz, February 200 I.

45 "Testing the Rank of the Hankel matrix: a statistical approach" by G. Camba-Mendez and G. Kapetanios, February $200 \mathrm{I}$.

46 "A two-factor model of the German term structure of interest rates" by N. Cassola and J. B. Luís, February $200 \mathrm{I}$.

47 “Deposit insurance and moral hazard: does the counterfactual matter?" by R. Gropp and J.Vesala, February 2001.

48 "Financial market integration in Europe: on the effects of EMU on stock markets" by M. Fratzscher, March $200 \mathrm{I}$.

49 "Business cycle and monetary policy analysis in a structural sticky-price model of the euro area” by M. Casares, March 2001 .

50 "Employment and productivity growth in service and manufacturing sectors in France, Germany and the US” by T. von Wachter, March 200 I.

5I "The functional form of the demand for euro area MI” by L. Stracca, March 200 I.

52 "Are the effects of monetary policy in the euro area greater in recessions than in booms?" by G. Peersman and F. Smets.

53 "An evaluation of some measures of core inflation for the euro area" by J.-L. Vega and M.A.Wynne, April 200I. 